\title{
A self-healable, moldable and bioactive biomaterial gum for personalised and wearable drug delivery
}

Shahbazi, Mohammad Ali; Shrestha, Neha; Pierchala, Malgorzata Karolina; Kadumudi, Firoz Babu; Mehrali, Mehdi; Hasany, Masoud; Préat, Véronique; Leeuwenburgh, Sander; Dolatshahi-Pirouz, Alireza

Published in:

Journal of Materials Chemistry B

Link to article, DOI:

$10.1039 /$ c9tb02156f

Publication date:

2020

Document Version

Publisher's PDF, also known as Version of record

Link back to DTU Orbit

Citation $(A P A)$ :

Shahbazi, M. A., Shrestha, N., Pierchala, M. K., Kadumudi, F. B., Mehrali, M., Hasany, M., Préat, V.,

Leeuwenburgh, S., \& Dolatshahi-Pirouz, A. (2020). A self-healable, moldable and bioactive biomaterial gum for personalised and wearable drug delivery. Journal of Materials Chemistry B, 8(19), 4340-4356.

https://doi.org/10.1039/c9tb02156f

\section{General rights}

Copyright and moral rights for the publications made accessible in the public portal are retained by the authors and/or other copyright owners and it is a condition of accessing publications that users recognise and abide by the legal requirements associated with these rights.

- Users may download and print one copy of any publication from the public portal for the purpose of private study or research.

- You may not further distribute the material or use it for any profit-making activity or commercial gain

- You may freely distribute the URL identifying the publication in the public portal 
Check for updates

Cite this: J. Mater. Chem. B, 2020, 8,4340

Received 1st October 2019

Accepted 7th March 2020

DOI: $10.1039 / c 9 t b 02156 f$

rsc.li/materials-b

\section{A self-healable, moldable and bioactive biomaterial gum for personalised and wearable drug delivery $\dagger$}

\author{
Mohammad-Ali Shahbazi, (DD ab Neha Shrestha, ${ }^{c}$ Malgorzata Karolina Pierchala, ${ }^{d}$ \\ Firoz Babu Kadumudi, ${ }^{d}$ Mehdi Mehrali, de Masoud Hasany, ${ }^{d}$ Véronique Préat, ${ }^{c}$ \\ Sander Leeuwenburgh (D) ${ }^{f}$ and Alireza Dolatshahi-Pirouz (D) *df
}

\begin{abstract}
One of the long-standing challenges in materials science involves synthesizing biomaterials that recapitulate important features of native biological tissues. Even though, the number of available biomaterials at the moment are virtually limitless, few of them has unlocked all the secrets of the human body by mimicking the combinatorial-like material properties of our tissues and organs. Inspired by the human body, we have developed a polymeric gum, which combines stretchability, toughness, strength, flexibility, and self-healing. It also exhibits a high bioactivity that can target and eliminate bacterial infections fast and reliably. Notably, this material is moldable into almost any complex shape, and therefore suitable as a building block for wearables designed to conform directly with the curved and personalized anatomy of patients. It also exhibits excellent drug retention and release capacity, which altogether makes it suitable for applications in personalized wearable drug-delivery devices.
\end{abstract}

In recent years, self-healing and stretchable biomaterials have received increasing interest in wearable devices, epidermal electronics, implants and cybernetics. ${ }^{1-6}$ Indeed, desirable materials for these applications must be able to blend perfectly with organs and tissues for long period without any unwanted outcomes, while at the same time retaining their predefined functions and inherent properties. These materials also need to mimic the complex and curvilinear architecture of the human body, as well as recapitulate some of the mechanical and biological abilities of the target tissue or organ. In this respect, some of the unique aspects of many organs and tissues in the body-including musculoskeletal, skin, cardiac and tooth-is their robustness, flexibility and ability to withstand dynamic forces from day-to-day activities as well as their ability to quickly remedy biological

\footnotetext{
${ }^{a}$ Department of Micro- and Nanotechnology, Technical University of Denmark, Ørsteds Plads, DK-2800 Kgs, Lyngby, Denmark

${ }^{b}$ Department of Pharmaceutical Nanotechnology, School of Pharmacy, Zanjan University of Medical Sciences, Zanjan, Iran

${ }^{c}$ Université catholique de Louvain, Louvain Drug Research Institute, Advanced Drug Delivery and Biomaterials, 1200 Brussels, Belgium

${ }^{d}$ Technical University of Denmark, Department of Health Technology, Center for Intestinal Absorption and Transport of Biopharmaceutical, 2800 Kgs, Denmark. E-mail: aldo@dtu.dk

${ }^{e}$ Department of Mechanical Engineering, Technical University of Denmark, $2800 \mathrm{Kgs}$, Lyngby, Denmark

${ }^{f}$ Department of Dentistry - Regenerative Biomaterials, Radboud University Medical Center, Philips van Leydenlaan 25, Nijmegen 6525 EX, The Netherlands

$\dagger$ Electronic supplementary information (ESI) available. See DOI: 10.1039/c9tb02156f
}

injuries inflected upon them. ${ }^{7}$ However, unfortunately, as we speak, a number of profound challenges need to be addressed to pave the road for such combinatorial materials. Because, how does one develop a biomaterial that is both sufficiently strong, flexible, load-bearing, and self-healing at the same time? Is such a design even feasible with non-toxic chemistry and without compromising biocompatibility and scalability? The long-standing conflict between toughness, strength and self-healing also stands in the way for achievements on this scale. ${ }^{8,9}$ We have surmounted the aforementioned obstacles using an ingenious, low-cost and green "design \& mixing" procedure of only two components.

Inspired by the hierarchical organization of materials such as spider silk, bone, nacre and wood, which simultaneously combine strength, flexibility and toughness, we have employed a similar hierarchical scheme based on hydrogen bonds to achieve the same portfolio of material properties in the laboratory. ${ }^{10,11}$ Hydrogen bonds are reversible; therefore our hypothesis is that this scheme also can facilitate self-healing properties because such weak bonds can break and re-form in a indefinite manner. This ability, in turn, can also facilitate high stretchability because of the continuous energy dissipated from bond breaking and re-forming during straining. ${ }^{6,12-14}$

Specifically, we have combined two materials-tannic acid (TA) and polyvinyl alcohol (PVA) - both of which are rich in hydroxyl groups prone to forming hydrogen bonds. ${ }^{15-17}$ Indeed, by simply mixing these two components we have successfully developed a unique PVA-TA biomaterial (referred to as PATA) 


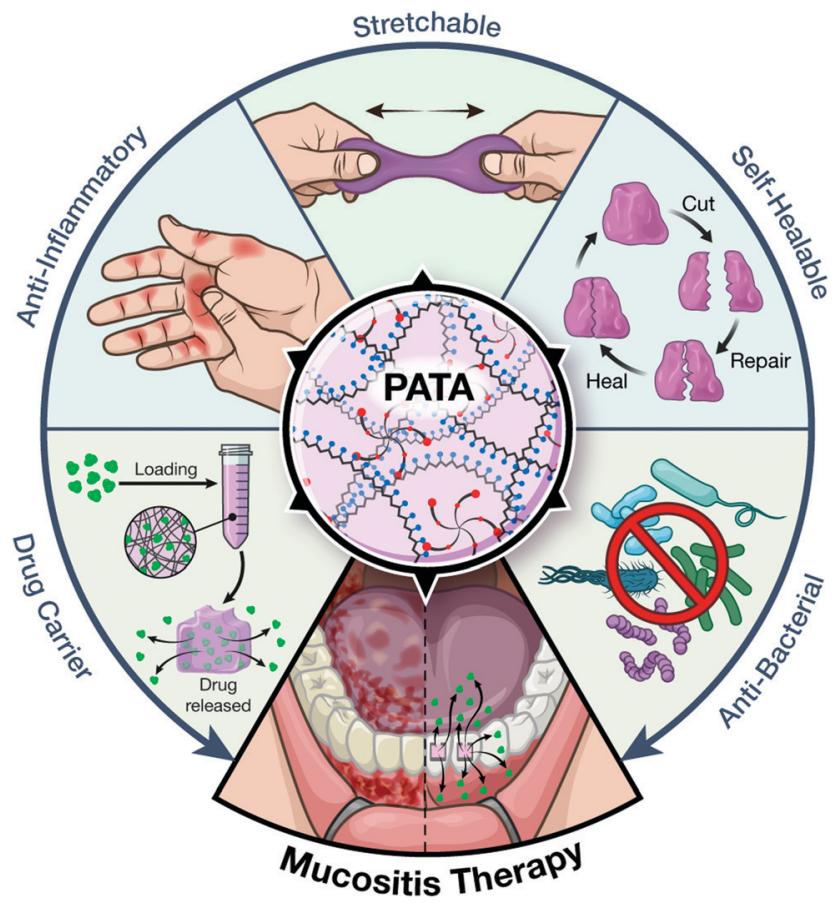

Fig. 1 The wide spectrum of properties that PATA exhibits are illustrated here. Indeed, PATA is highly stretchable and exhibits antibacterial, antiinflammatory and self-healing properties. It is also capable of long-term drug delivery into the oral cavity. Finally, PATA is moldable and can be custom-fitted within wearable drug delivery devices. Herein, we have used this concept to develop a wearable device that specifically targets mucositis.

that in its consistency and appearance in many ways resembles chewing gum. This gum-like biomaterial can stretch up to $30000 \%$ of its original length before failure, rapidly and repeatedly selfheals within seconds, has an elastic modulus of $\sim 160 \mathrm{kPa}$ and can be molded into complex and curvilinear architectures similar to those in the human body. Moreover, since TA is widely recognized for its pronounced anti-oxidant capacity, our unique biomaterial also displays various desirable biological properties including antibacterial and anti-inflammatory efficacy. Since the biomaterial itself shares hydrogel-like characteristics it can be used as a drug carrier as well (Fig. 1). ${ }^{18,19}$ For these reasons, we truly believe that we have developed an unusual material that fulfills a wide range of biomaterial criteria necessary in the field of biomedical engineering without compromising manufacturing time and cost. Advantageously, this novel material is highly moldable. Therefore, we foresee that it can be used as a building component for custom-built wearables that can be manufactured to fit perfectly with the anatomy of the target tissue in terms of shape, size and architecture. Furthermore, because the material is self-healing, flexible and tough-like human tissue-it could potentially integrate completely with the human body in a personalized manner.

We have exploited these exciting characteristics to develop a customizable oral drug-delivery device to target mucositis, one of the many adverse effects of chemo- and radiotherapy. ${ }^{20,21}$ In simple terms, mucositis is characterized by painful inflammation in the oral cavity and potentially lethal bacterial infections, which TA can readily target and eliminate (Fig. 1). Specifically, we employed a laser cutting approach to manufacture a custommade holder that can attach to a patient's teeth, and which our moldable material could fit perfectly within to deliver drugs in a sustainable manner within the oral cavity (Fig. 1). Indeed, the speed and low-cost of the laser cutting methodology, in combination with our highly moldable drug-eluting biomaterial, could enable on-demand and on-site manufacturing of personalized wearables to target a wide range of diseases in a patient-specific manner. In this scenario, the laser cutting technology can be combined with 3D scanning technology to yield drug delivery-devices that can perfectly meld with a patient's anatomical features. In summary, our proofof-concept work demonstrates the potential of the aforementioned biomaterial gum for the development of custom-made and personalized drug-delivery devices.

\section{Results}

Polyvinyl alcohol (PVA) is a synthetic polymer with many hydroxyl groups located on its side chains (Fig. 2a); this property makes it highly water-soluble. ${ }^{16}$ PVA is also non-toxic, biodegradable and biocompatible and is therefore considered to be one of the most suitable polymeric biomaterials for biomedical engineering applications. ${ }^{22}$ Tannic acid (TA), on the other hand, is a naturally occurring compound that exists within the bark and fruits of trees and plants. ${ }^{15,23}$ In brief, TA is made from a central core of polyhydric alcohols that are covalently linked to five digallic acid units (Fig. 2a). Each of the digallic acid units contains numerous hydroxyl groups, which endow TA with pronounced anti-oxidant and free radical scavenging properties. Consequently, TA is recognized by many experts for its antimicrobial, anticarcinogenic and antibacterial properties. For these reasons, TA has found a broad application base within the biomedical community. ${ }^{24}$ In view of its abundant hydroxyl side groups, TA can also facilitate the formation of hydrogen-bonded networks, ${ }^{17}$ especially with alcoholcontaining polymers such as PVA. We therefore hypothesize that a simple water solution blending of PVA and TA into PVA-TA (PATA) can yield a hydrogel via the formation of $\mathrm{OH}-\mathrm{OH}$ hydrogen bonds. Since PVA alone also crosslink physically via polymer entanglement and $\mathrm{OH}-\mathrm{OH}$ bonding we expect a hierarchical bonding scheme to persist in PATA consisting of crosslinks of tuneable binding strengths. In the following sections, we characterize the chemical, self-healing and mechanical properties of this novel biomaterial system. We also examine its degradation profile, drug-loading capacity and biological performance before testing its use as a customizable drug-delivery device.

\section{Chemical and thermal characterization}

The biomaterial gum formed almost immediately after mixing and vortexing PVA and TA solutions together. From the Fouriertransform infrared spectroscopy (FTIR) analysis presented in Fig. $2 \mathrm{~b}$, it is clear that hydrogen bonds are one of the driving forces behind the transformation of PVA and TA into solid PATA. Specifically, the stretching vibrations of the hydroxyl group $(-\mathrm{OH})$ for PVA $\left(3340 \mathrm{~cm}^{-1}\right)$ and TA $\left(3320 \mathrm{~cm}^{-1}\right)$ in PATA 
a

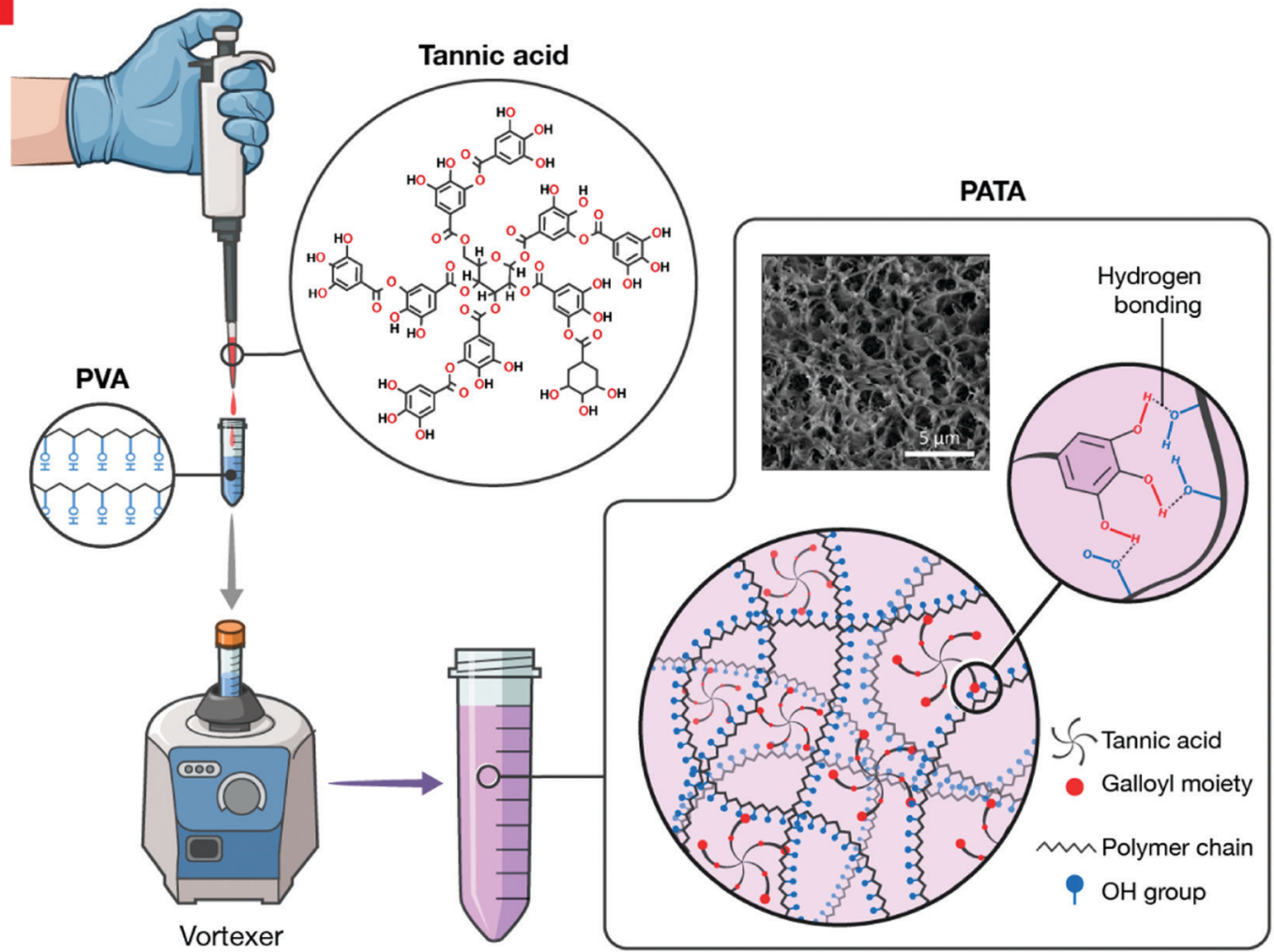

b

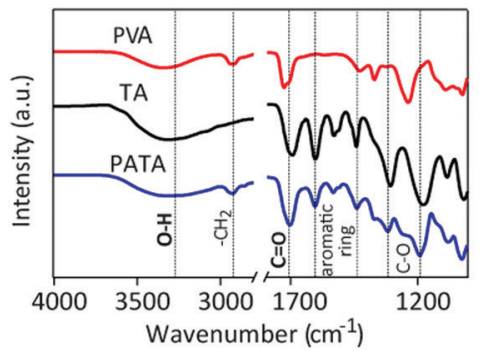

e

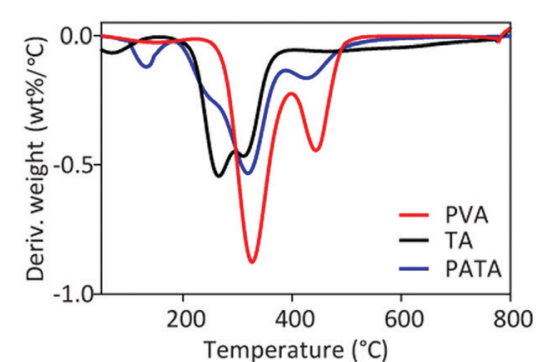

d

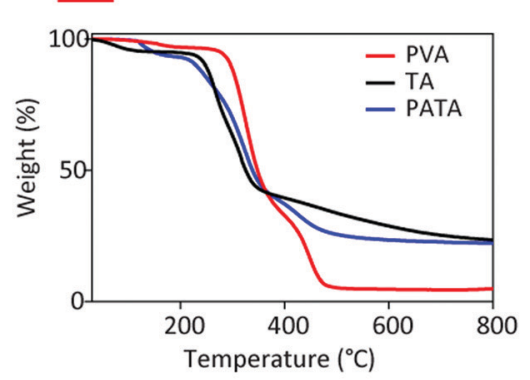

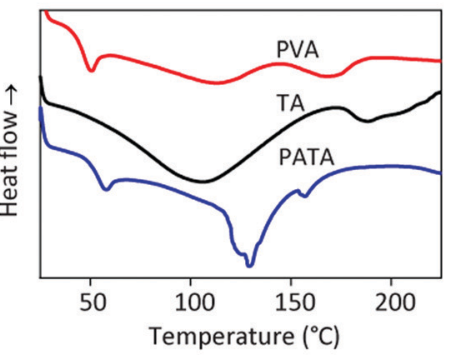

f

\begin{tabular}{|c|c|c|c|}
\hline Type DSC & $\mathrm{T}_{\mathrm{g}}\left({ }^{\circ} \mathrm{C}\right)$ & $\mathrm{T}_{\mathrm{m}}\left({ }^{\circ} \mathrm{C}\right)$ & $\Delta \mathrm{H}(\mathrm{J} / \mathrm{g})$ \\
\hline PVA & $49.6 \pm 0.6$ & $168.9 \pm 0.6$ & $9.5 \pm 1.9$ \\
\hline PATA & $55.3 \pm$ & $126.0 \pm 4.4$ & \pm 7.3 \\
\hline Type TGA & $\mathrm{T}_{10 \%}\left({ }^{\circ} \mathrm{C}\right)$ & $\mathrm{T}_{50 \%}\left({ }^{\circ} \mathrm{C}\right)$ & Residue at $800^{\circ} \mathrm{C}$ \\
\hline PVA & $298.3 \pm 1.3$ & $348.8 \pm 0.9$ & \\
\hline TA & $245.8 \pm$ & $325.4 \pm 0.9$ & $23.3 \pm 0.5 \%$ \\
\hline PATA & $231.2 \pm 0.9$ & $337.5 \pm 1.1$ & $21.9 \pm 0.6 \%$ \\
\hline
\end{tabular}

Fig. 2 Chemical characterization of PATA. (a) Schematic depiction of the chemistry behind the formation of our hydrogel-like gum, the synthesis process, and corresponding scanning electron microscopy (SEM) image of PATA. (b) FTIR spectra, (c) DSC analysis, (d) TGA analysis, (e) DTG analysis, and (f) the tabulated thermal values retrieved from DSC, TGA and DTG for PVA, TA, and PATA.

are in accordance with the formation of hydrogen bonds between hydroxyl groups present in PVA and TA. ${ }^{17}$ On the other hand, the stretching vibrations of $\mathrm{C}=\mathrm{O}$ in PVA at $1735 \mathrm{~cm}^{-1}$ and TA at $1700 \mathrm{~cm}^{-1}$ are shifted to $1710 \mathrm{~cm}^{-1},{ }^{25,26}$ indicating the existence of yet another and stronger type of intermolecular hydrogen bond between $\mathrm{C}=\mathrm{O}$ and $-\mathrm{OH}$. Furthermore, the characteristic band for stretching vibration of methylene $\left(-\mathrm{CH}_{2}\right)$ from PVA $\left(2930 \mathrm{~cm}^{-1}\right)$ and the stretching vibrations 
from the TA aromatic rings at 1610 and $1450 \mathrm{~cm}^{-1}$ are clearly visible in PATA, which confirms the assembly of PATA from its precursor components PVA and TA. ${ }^{26}$

A number of studies have established a relationship between high polymer mobility and a low glass transition temperature $\left(T_{\mathrm{g}}\right){ }^{27}$ Likewise, the melting and decomposition points of a material are also linked with important properties such as crystallinity, elasticity and stability; parameters that are intimatly linked with mechanical properties and self-healing capacity of any given material. For these reasons, we carefully characterized the thermal properties of PATA to gain a better mechanistic understanding of its mechanical and self-healing properties.

In this regard, Differential Scanning Calorimetry (DSC) is a widely recognized tool for probing both the energy required for breaking crystalline regions and the $T_{g} ;{ }^{28}$ whereas Thermal Gravimetric Analysis (TGA) can probe the various thermal phases of materials. ${ }^{28}$ We used both methodologies to study the fundamental characteristics of PATA. As shown in Fig. 2c and $\mathrm{f}$, the DSC curves of PVA revealed a $T_{\mathrm{g}}$ at $49.6{ }^{\circ} \mathrm{C}$ (typical values range between 37.5 and $\left.88.1{ }^{\circ} \mathrm{C}\right) .{ }^{29-31}$ which remained largely unchanged after TA incorporation. Its melting temperature, on the other hand, was around $169{ }^{\circ} \mathrm{C}$, which is a bit lower than usual (typical values range between 193 and $220{ }^{\circ} \mathrm{C}$ ). ${ }^{29,30}$ It is noteworthy that this value dropped to $126{ }^{\circ} \mathrm{C}$ after the incorporation of TA. The DSC results therefore confirm a high molecular mobility within our PATA biomaterial which in turn could facilitate autonomous self-healing. The PVA melting enthalpy $(\Delta H)$ retrieved from the DSC data was also almost 9fold smaller than that retrieved for PATA. This finding might simply be a result of the manifold higher $\Delta H$ value retrieved for TA alone.
The TGA curves (Fig. $2 \mathrm{~d}$ and $\mathrm{f}$ ) indicated that the thermal resilience of PVA decreased a bit after the incorporation of TA. To be more specific, we transformed the TGA curves into Differential Thermal Gravimetric (DTG) curves. From here, we observed two obvious degradation peaks for PVA over the temperature range of $200-480{ }^{\circ} \mathrm{C}$, which were slightly shifted to lower values after the addition of TA. In the PATA case, a sharp peak at $\sim 124{ }^{\circ} \mathrm{C}$ was also observed, which could be ascribed to the evaporation of moisture and the large amount of water that was trapped in the polymer network; and thus a strong indicator of hydrogel-like characteristics. From the TGA and DTG curves, we can thus conclude that the presence of TA did not negatively affect the thermal stability of PVA but instead facilitated the formation of a highly hydrated biomaterial.

\section{Stability studies}

To optimize the physicochemical properties of PATA, we tested seven different preparation conditions. In all methods, PVA was dissolved in PBS ( $\mathrm{pH}$ 7.4) while TA solution was prepared in different solvents including, water, PBS, and sodium hydroxide $(\mathrm{NaOH})$ with different molarities. The physiochemical properties of PATA-such as its degree of swelling, water retention and stability in different solvents-are presented in Fig. 3. It is evident that PATA shares many of the same characteristics as hydrogels, albeit with a significantly lower swelling ratio and water content than most conventional hydrogels (Fig. 3). The swelling ratio of PATA was strongly dependent on the presence of $\mathrm{NaOH}$ in the TA solution; the highest $\mathrm{NaOH}$ concentration resulted in the highest swelling rate (Fig. 3a). On the other hand, the water content remained fairly stable (between 55\% and 70\%) depending on the aqueous solvent of TA (Fig. 3b). We also performed water

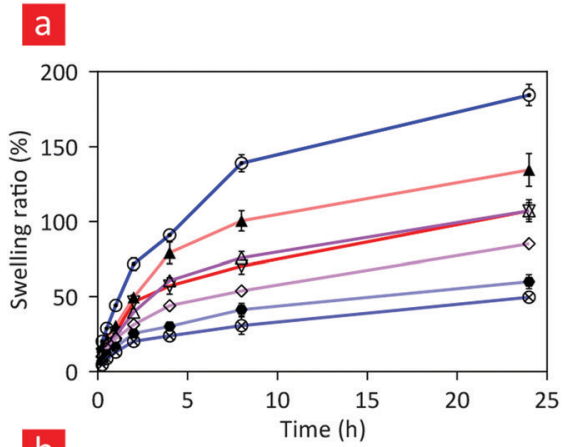

b

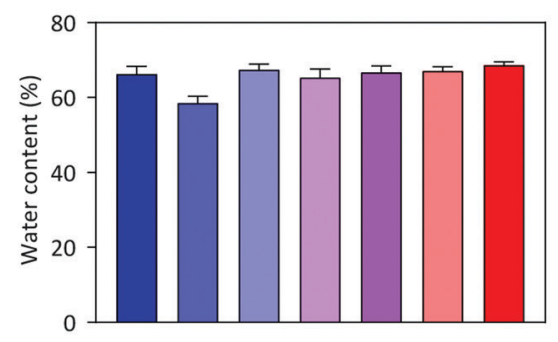

$\multimap$ PATA (1M NaOH)

\& PATA (water)

- PATA $(0.05 \mathrm{M} \mathrm{NaOH})$

$\diamond$ PATA $(0.25 \mathrm{M} \mathrm{NaOH})$

$\triangle$ PATA $(0.5 \mathrm{M} \mathrm{NaOH})$

$\_$PATA $(0.75 \mathrm{M} \mathrm{NaOH})$

$\rightarrow$ PATA (PBS)

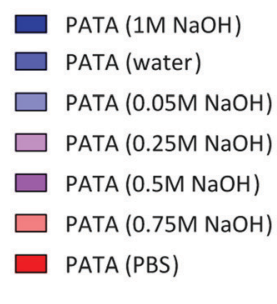

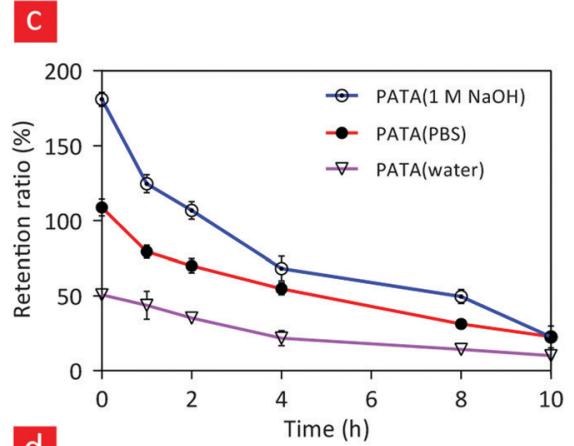

d

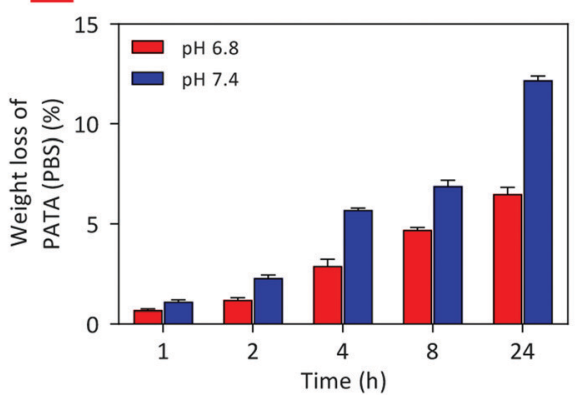

Fig. 3 Physiochemical characterization of PATA. In brief, PVA was dissolved in PBS ( $\mathrm{pH} 7.4$ ) and TA in various solvents, including water, PBS ( $\mathrm{pH}$ 7.4) and $\mathrm{NaOH}$ with different molarities to test (a) swelling ratio, (b) water content, (c) water retention ratio, and (d) weight loss of the prepared composites. 
retention studies for three biomaterials with the highest, middle and lowest swelling ratios (Fig. 3c). We found that the water retention decreased to less than $35 \%$ after 10 hours for all conditions. Even though the water content is substantially lower than that of most hydrogels $(70-99 \%),{ }^{32,33}$ the water retention profile is more prolonged compared with conventional hydrogels, which dehydrate almost immediately when moved to non-aqueous environments. This is critical because many of the properties that hydrogels exhibit are conditioned by their hydration. ${ }^{7,9,33-35}$ PATA was also fairly stable in PBS with a pH value of either 6.8 or 7.4; the best stability observed at a $\mathrm{pH}$ of 6.8 . The total mass loss ranged from $6.5 \%$ at $\mathrm{pH} 6.8$ to $12 \%$ at $\mathrm{pH} 7.4$ after 24 hours (Fig. 3d). We attribute most of this mass loss to TA because nearly $40 \%$ of the entrapped TA was released into the environment after 24 hours at a $\mathrm{pH}$ of 7.4; this release was nearly two-fold higher than that at a pH of 6.8 (Fig. S1, ESI $\dagger$ ).

Overall, we can conclude from the results listed in Fig. 3 that PATA displays hydrogel-like properties but not in a conventional sense. Notably, PATA displayed high water retention and stability in PBS over water, rendering it useful in both aqueous and dry conditions. Moreover, our assumption was that a higher swelling ratio would lead to a more rapid release of TA, which is not desired; we conversely assumed that the lowest swelling ratio might reduce the drug-release rate and thus decided to exclude the $\mathrm{NaOH}$ conditions in further down-stream studies. ${ }^{36,37}$ Therefore, due to its stability and reasonable swelling ratio in PBS, we selected this physiological medium for additional studies to optimize drug delivery kinetics for applications in drug delivery.

\section{Self-healing properties}

Tissues of the human body are strong, resilient, adaptable and capable of undergoing self-healing when damaged. For any device to blend completely with the organs and tissues of the body, it must encompass at least some of the aforementioned properties. This situation is particularly true for wearable devices intended to be used on flexible, curvilinear or load-bearing parts of the human body. Here, we demonstrate that PATA is a flexible, moldable and self-healing material capable of making wearables more "human-friendly." We have showcased some of these exciting properties in photographic images, which are displayed in Fig. 4. From Fig. 4a, it is evident that destructed PATA sections can immediately self-heal; and that the material itself is highly moldable and stretchable, mainly as a result of abundant hydrogen bonds in the structure of PATA as described in the previous section. Notably, excellent mechanical recovery was observed after reconnecting broken PATA's for only 240 seconds (Fig. 4b). PATA healed rather remarkably, and the fracture gap was almost completely refilled after 20 seconds (Fig. 4c). This finding was confirmed through Scanning Electron Imaging (SEM) as well (Fig. 4d), and Fig. S2 (ESI $\dagger$ ) further supports the above-listed properties in terms of polymer stretchability of healed parts and their mechanical integrity.

\section{Mechanical analysis}

Generally speaking, self-healing behavior is facilitated by polymer chain mobility, whilst strength is typically proportional to the density and degree of crosslinking of the matrix. ${ }^{38}$ Accordingly, PATA's exceptional self-healing ability might compromise its mechanical strength since crosslinking density is an antagonist to chain mobility. Moreover, the mechanical properties of biomaterials are crucial for optimal performance within the demanding environments of the human body. In Fig. 5 we have therefore performed an elaborate characterization of PATA's mechanical properties as an "add-on" to the self-healing analysis presented in the previous section.

The specimens were evaluated in tensile mode to retrieve stress, strain and toughness at fracture point (Fig. 5). To this end, a series of cyclic stress-strain curves were obtained and displayed in Fig. 5a and b together with photographic images of the stretched specimens. We did not push the samples to the limit-we tested only to a maximum strain value of $15000 \%$ to perform many consecutive cycles. But, as can been concluded from ESI, $\dagger$ Fig. S3, PATA could stretch to $30000 \%$ of its original length. In comparison, most elastomers display a maximum elongation between $100 \%$ and $1000 \%{ }^{55}$ Recently, however, a team at Stanford University developed an ultra-stretchable PDMS-based polymer that could elongate to over $10000 \%$ its original length. ${ }^{5}$ We also note that PATA exhibits an ultimate stress (between 35 and $55 \mathrm{kPa}$ ) and a tensile modulus that is substantially higher (100-160 kPa) than that of most hydrogels. ${ }^{4,17,39}$ Moreover, we also notice that the mechanical properties of PATA were in general higher in the PBS than in water (Fig. 5c); which could be due to a higher ionic strength of PBS and the associated enhancement in hydrogen bonding forming capacity compared to water. Advantageously, PATA shows a high mechanical recovery at around $100 \%$ after being healed for 2 hours and could keep this recovery efficiency constant for many repeated cycles (Fig. 5f).

According to the stability results shown in Fig. 3 and ESI, $\dagger$ Fig. S1, PATA experienced weight losses caused by the release of TA. This observed TA release might compromise the long-term mechanical integrity of PATA, since TA is the mediator of many of its exciting mechanical and self-healing properties discussed thus far. To address this concern, we performed a series of mechanical analyses following TA release for up to 72 hours (Fig. S4, ESI $\dagger$ ). From these data, it is evident that TA release did not compromise the mechanical properties of PATA. We speculate that this interesting phenomena is most likely caused by the presence of substantial amounts of unbound TA; which therefore does not affect the mechanical integrity of PATA after their release from the system.

We also examined the mechanical recovery of PATA after drying and rehydration (24 hours) (Fig. S5, ESI $\dagger$ ), since practical usage dictates that PATA needs to be dried to enable its longterm storage. Interestingly, the results shown in ESI, $\dagger$ Fig. S5 confirm that the mechanical properties of PATA remained largely the same after a drying-rehydrating cycle. Overall, these results indicate that PATA displays sufficient mechanical stability for both long-term usage and storage purposes.

\section{A customized oral drug delivery device}

Wearable healthcare devices have been developing at a rapid pace, and their spectrum of applications appears virtually 


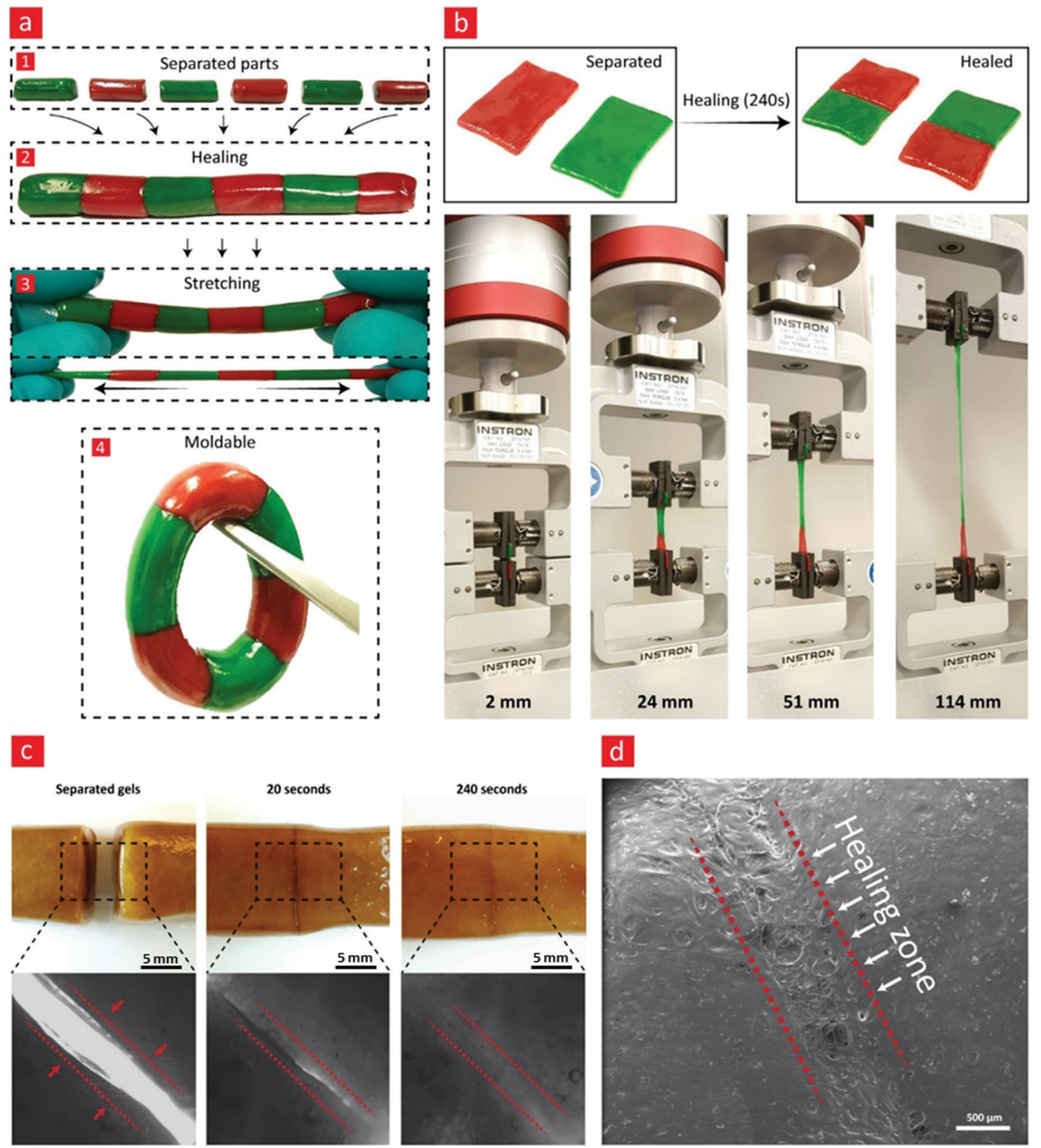

Fig. 4 Self-healing properties of PATA. (a) Hydrogels loaded with green and red dyes were prepared and cut into small pieces to test the self-healing, moldable and stretchable properties of PATA. As shown, pieces with different colors were rapidly healed by putting the fresh surfaces into contact with one another. Flexibility and moldability of the self-healed hydrogel is shown in section a4. (b) Stretchability of two separate pieces of PATA after selfhealing. The images shows that PATA can extend more than 50 times its original length after healing - without any rupture. (c) Photographs of the healing process and corresponding optical images. (d) SEM image of the healed area after $240 \mathrm{~s}$ of healing.

limitless at the moment. ${ }^{3}$ They especially hold great promise as personalized devices that can increase the efficacy of therapy by blending in with the shape, size, weight and specific anatomy of their wearer. Despite the overwhelming interest that wearable devices have garnered, they have not yet unleashed their full potential in the field of orthopedics and dentistry. Here, we have used our moldable and drug-retainable PATA as a drugeluting carrier within a wearable oral delivery device to target muscositis. Mucositis is defined as the inflammation and ulceration of mucous tissues in the digestive tract and oral cavity; ${ }^{20,21}$ and it typically arises after intensive chemo- and radiotherapy. Our hypothesis is that PATA possesses sufficient anti-inflammatory and anti-bacterial properties to prevent mucositis from occurring during cancer treatment. In combination with painkilling drugs (analgesics), we propose that PATA can be used to generate an oral delivery device for mucositis therapy. The idea is that this device can eliminate mucositis through its anti-inflammatory and bacteria-killing abilities, while at the same time preventing the pain and agony associated with the disease. 


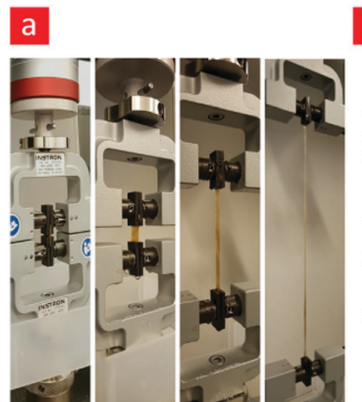

$2 \mathrm{~mm} 11 \mathrm{~mm} 69 \mathrm{~mm} 265 \mathrm{~mm}$ c
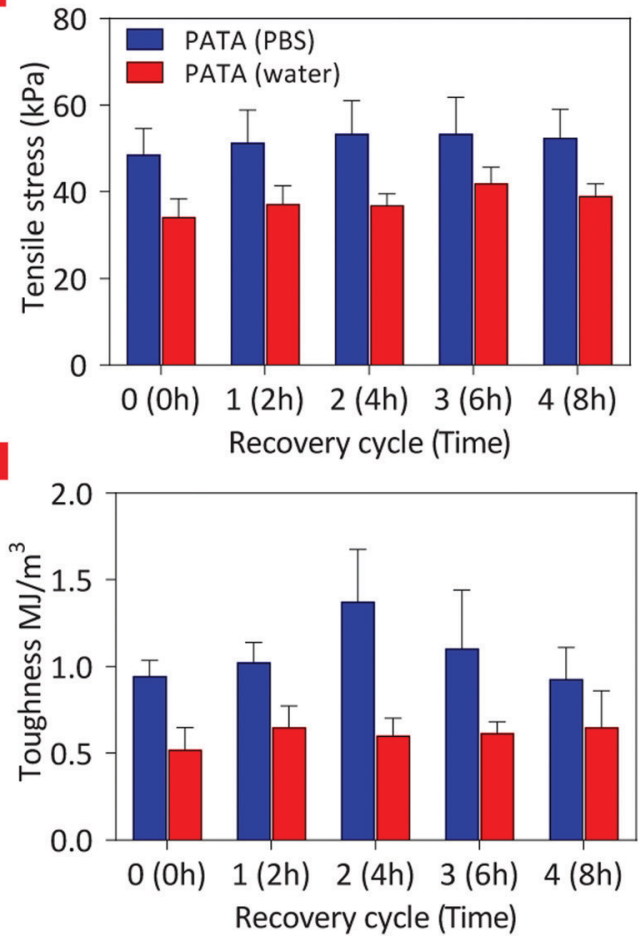

b
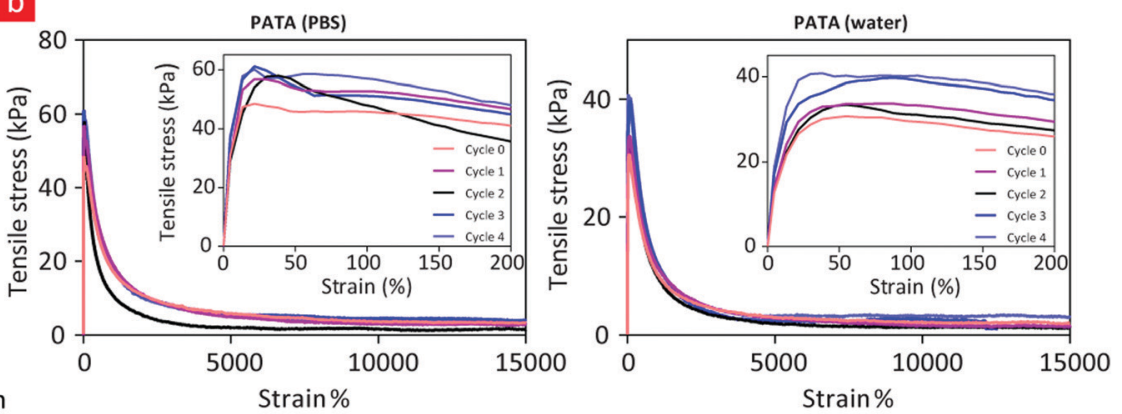

d

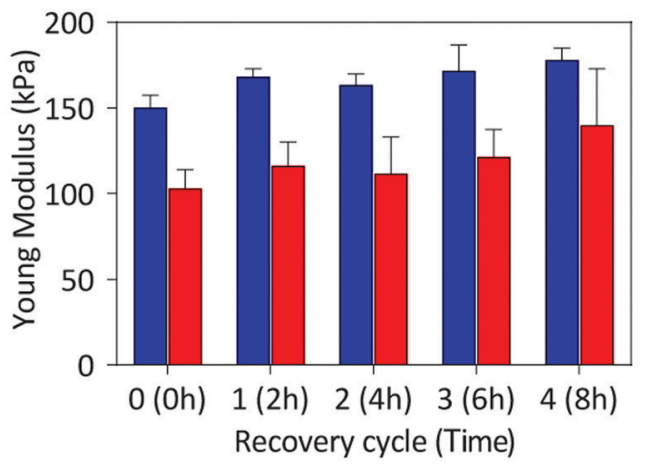

f

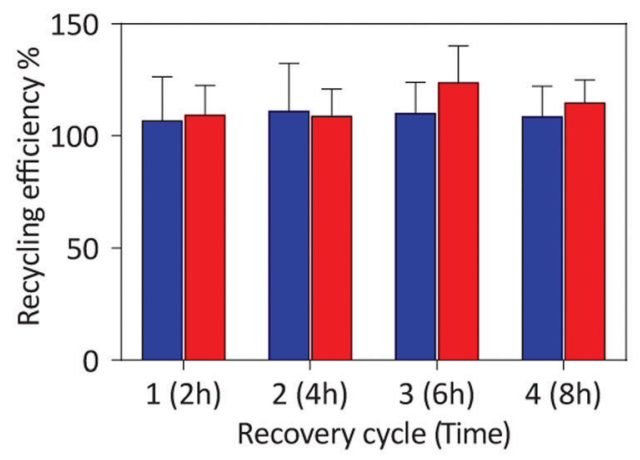

Fig. 5 Mechanical analysis of PATA. (a) Snapshots showcasing the high stretching property of PATA. Specifically, the images show that PATA could be stretched to 130 times its initial length, from $2 \mathrm{~mm}$ to more than $265 \mathrm{~mm}$ without any breakage. (b) Cyclic tensile-strain curves (up to five cycles) corresponding to PATA hydrogels prepared in either PBS or water. (c) The tensile stress, (d) Young modulus, (e) toughness and (f) self-healing efficiency of the respective hydrogels are displayed here.

Therefore, we investigated the antibacterial properties of PATA (Fig. 6a-c) on $S$. aureus, which is one of the main causes of oral infection in patients suffering mucositis. ${ }^{40}$ The results depicted here clearly show that TA released from PATA can inhibit the growth of $S$. aureus bacteria as compared to a control PBS buffer solution (Fig. 6a). In addition, the area devoid of bacterial growth (inhibition zone) grew steadily from around $9 \mathrm{~mm}$ to $15 \mathrm{~mm}$ in 24 hours (Fig. 6b). SEM imaging confirmed this interesting trend, as the bacterial growth declined as compared to the control sample when $S$. aureus was treated with TA released from the hydrogel for 1 hour. Notably, the SEM images indicate that bacteria were completely eradicated after being exposed to TA released from PATA for 24 hours, since only debris structures were observed. From ESI, $\dagger$ Fig. S6, it is evident that released TA was the primary ingredient responsible for the bacteria growth inhibiting properties of PATA.
Next, we examined the anti-oxidant and anti-inflammatory properties of PATA (Fig. 6d-g). Because one of the important hallmarks of inflammation is intimately linked with oxidative stress caused by free radicals released by the body's own immune cells; ${ }^{41}$ we therefore screened the free radical-scavenging capacity of PATA. Indeed, PATA effectively removed important free radicals such as DPPH and ABTS within a few hours (Fig. 6d and e). We also examined the reducing power and reductive oxidative stress (ROS) reduction capacity of TA released from PATA (Fig. $6 \mathrm{f}$ and $\mathrm{g}$ ) at two different $\mathrm{pH}$ values (6.8 and 7.4). The $\mathrm{pH}$ of the oral cavity, which is the target site of our device, is around 6.8. ${ }^{42}$ Besides, $\mathrm{pH} 7.4$ is the normal $\mathrm{pH}$ in many parts of the human body and is thereby recognized as a gold standard in most biological assays. Our results indicate that, similar to DPPH and ABTS studies described above, the reducing power was higher for TA released at a neutral $\mathrm{pH}$ value compared with 
a

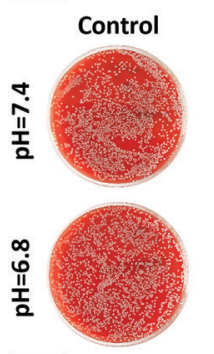

C
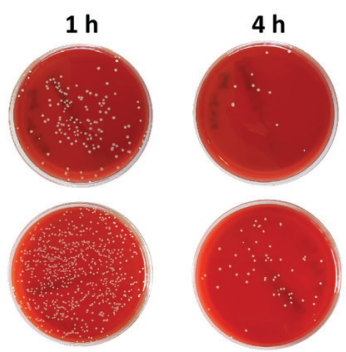

b
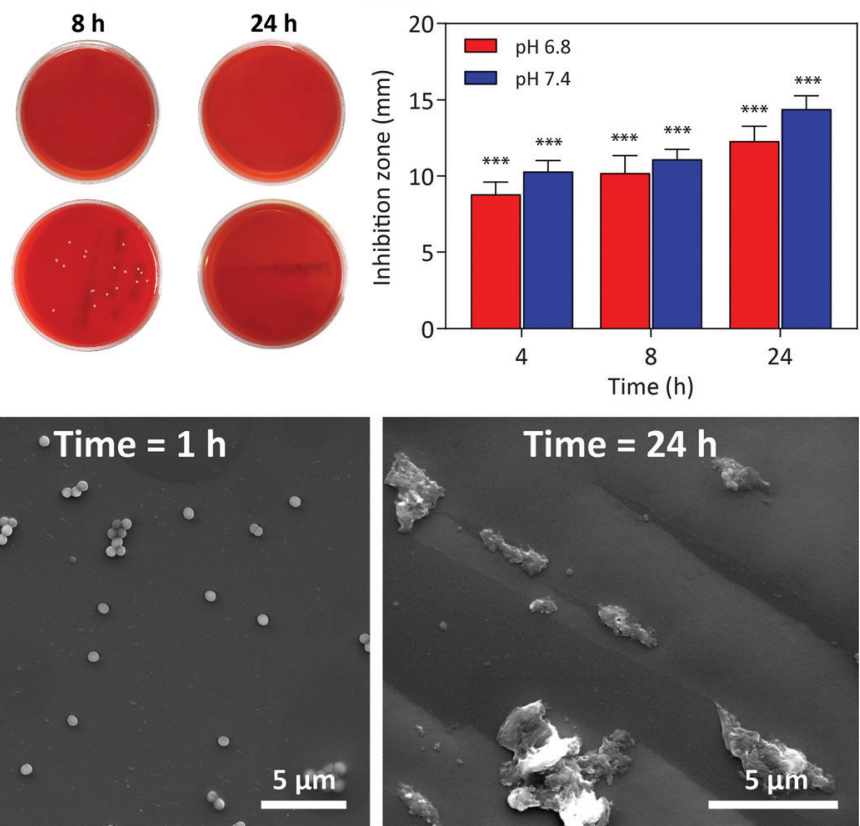
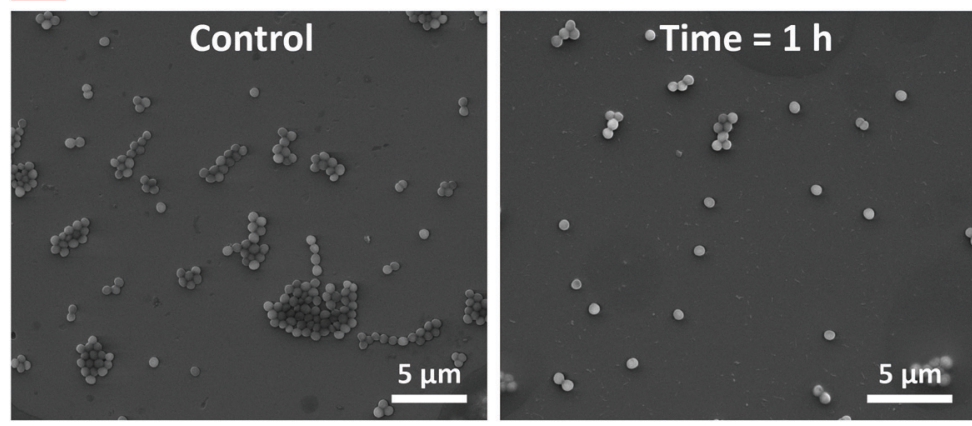

e ABTS $^{+}\left(2,2^{\prime}\right.$-azino-bis(3-ethylbenzothiazoline-6-sulphonic acid))

d

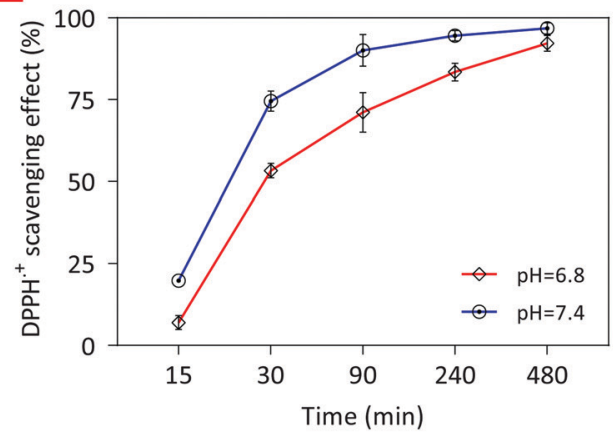

f

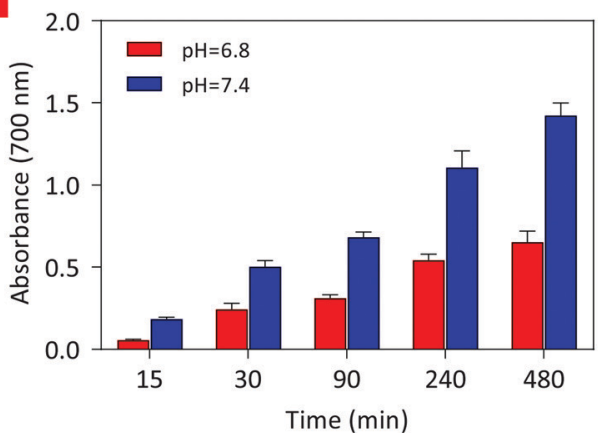

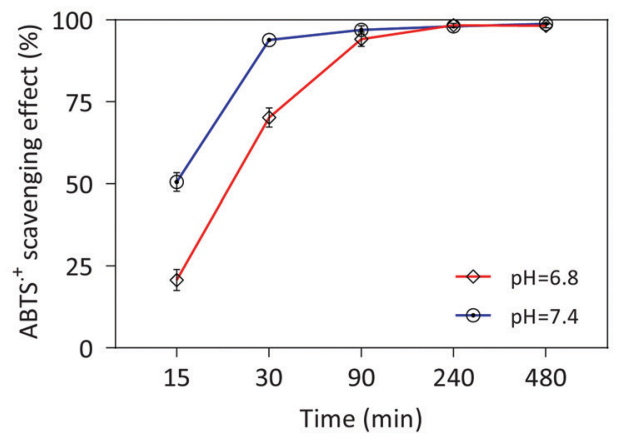

g

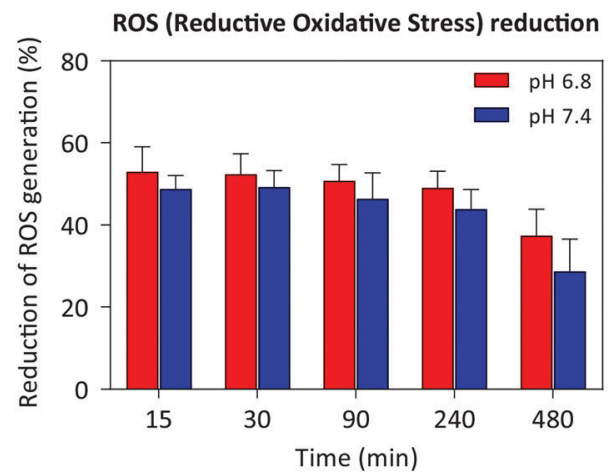

Fig. 6 Antibacterial and antioxidant activity of PATA. (a) The growth of S. aureus on an agar plate after treatment for $24 \mathrm{~h}$ with TA released from PATA for $1,4,8$, and $24 \mathrm{~h}$ at the $\mathrm{pH}$ values of 6.8 and 7.4 of the release media. (b) Quantitative values of inhibition zones against $S$. aureus due to TA released from PATA. (c) SEM images of bacteria treated with PBS (pH 7.4; control) or TA released from PATA for $1 \mathrm{~h}$ and $24 \mathrm{~h}$. (d) DPPH scavenging effect, (e) ABTS ${ }^{+}$ scavenging effect, (f) reducing power of PATA at two different $\mathrm{pH}$ values, and (g) anti-ROS activity stemming from the PATA gel at different time points.

a more acidic buffer. Furthermore, the ROS reduction capacity was not significantly affected by the $\mathrm{pH}$ value of the release media. Notably, both the reducing power and ROS values were substantial demonstrating the strong anti-inflammatory properties of PATA. Based on ESI, $\dagger$ Fig. S7, it is evident that these antiinflammatory properties primarily stem from TA. Indeed, TA displayed a much higher free radical scavenging effect than vitamin $\mathrm{E}$ ( $\alpha$-tocopherol); which is considered to be among the 
best free-radical scavengers. ${ }^{43}$ We therefore also reason that the better bioactivity observed at $\mathrm{pH} 7.4$ is most likely caused by the higher degree of TA release from PATA at this condition compared with release at pH 6.8 (Fig. S1, ESI $\dagger$ ).

Finally, we developed a customized wearable holder through laser printing and exploited the "easy-to-mold" feature of PATA to fit the material nicely into this holder, thereby fabricating a novel and versatile wearable oral drug delivery device (Fig. 7a and b). Then, doxepin-a widely used analgesic in mucositis treatment ${ }^{44}$-was loaded into PATA and the release profile of both TA and doxepin was followed for one week (Fig. 7c). A gradual and sustained release profile was evident for both compounds during this time period. Moreover, doxepin loading did not change the mechanical and self-healing properties of
PATA as evident from the results displayed in ESI, $\dagger$ Fig. S8. We also observed that TA released from PATA strongly reduced TNF- $\alpha$ production by J774 macrophages (Fig. 7d). To ensure that the TA dose was not cytotoxic to nearby epithelial cells, we tested its impact on the viability of three common types of epithelial cells (primary, Caco-2 and CAL-17 epithelial cells). ${ }^{45}$ Interestingly, the viability remained close to $100 \%$ for all cell lines regardless of the $\mathrm{pH}$ value for up to 24 hours (Fig. 7e and Fig. S9, ESI $\dagger$ ). We also examined chemotherapy-induced apoptosis (induced by 5-Fluorouracil (5FU) exposure) of primary epithelial cells in the presence of doxepin-loaded PATA using a combined DAPI and TUNEL staining assay (Fig. 7f). DAPI stains all nuclei blue, while cells undergoing apoptosis are additionally stained by green TUNEL, thereby giving rise to turquoise-colored cells (apoptotic cells). a

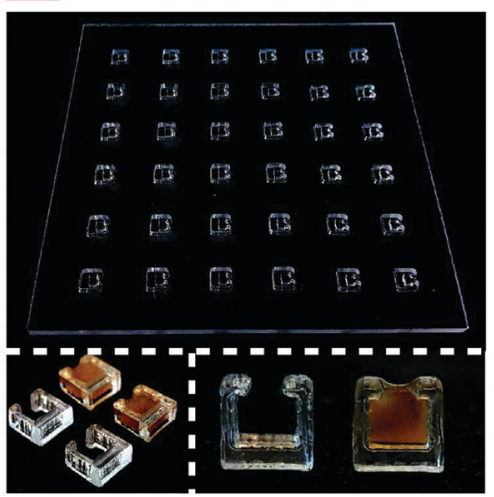

C

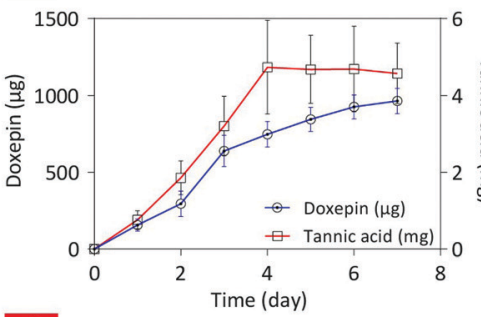

f

Control

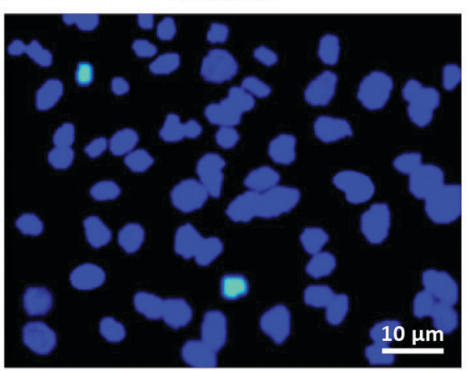

b

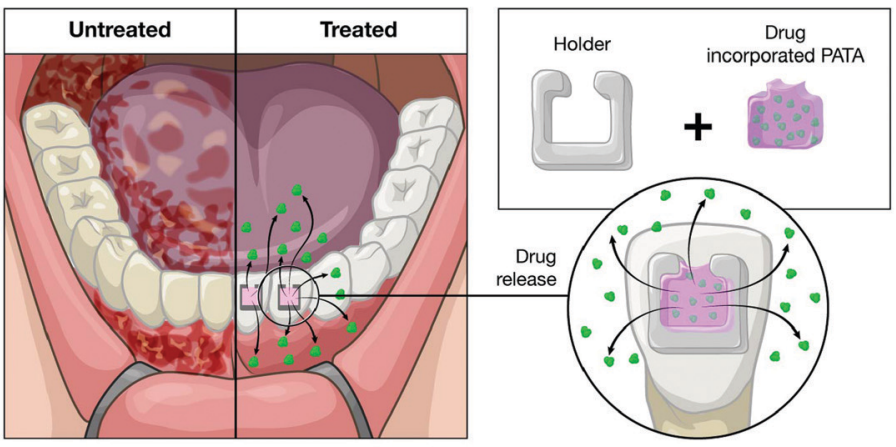

d

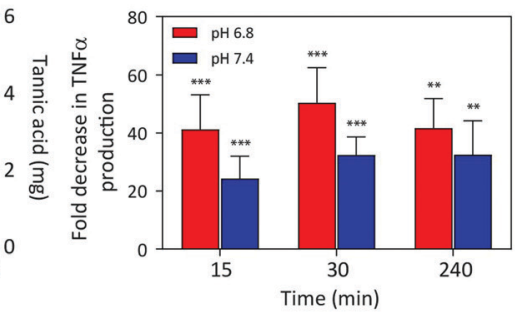

5FU

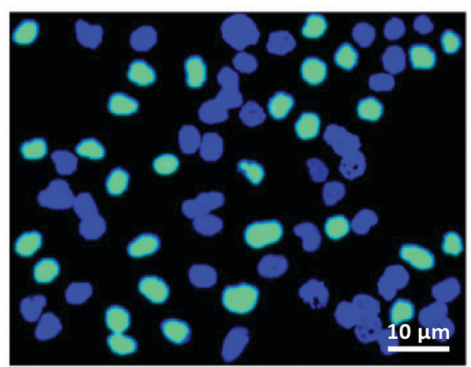

e

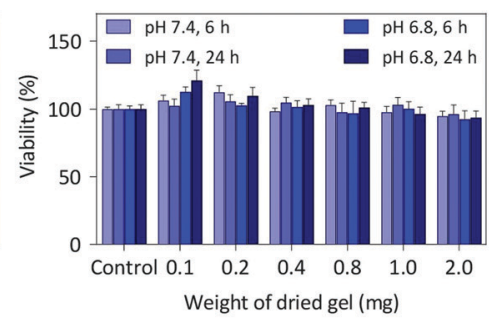

$5 F U+T A$

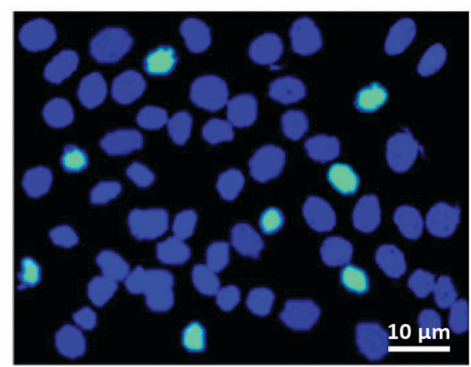

Fig. 7 A customized and wearable drug delivery device. (a) Photographic images demonstrating a successful molding of PATA within custom-built holders as wearable device for oral drug delivery. (b) A schematic showcasing the working principle behind its application for sustained drug release in the oral cavity after fixation onto the patients tooth. (c) The release profile of doxepin and TA from the gels inserted within the holder. Saliva mimicking medium was used for release study. (d) Strong reduction of TNF- $\alpha$ production in J774A.1 macrophages treated with a LPS solution caused by TA released from the PATA biomaterial at different time points. The values represent fold decrease in comparison to the positive control samples treated with LPS solution only. (e) Viability of primary epithelial cells treated with PATA for $6 \mathrm{~h}$ and $24 \mathrm{~h}$ at the pH values of 6.8 and 7.4. (f) Fluorescence imaging of cell apoptosis after treatment with 5-fluorouracil (5FU) alone and 5FU + TA. The images are merged panels of blue color corresponding to the cell nuclei and green color corresponding to apoptotic cells. 
From these images, it was evident that TA could remedy the 5FU-induced cell apoptosis.

\section{Discussion}

Wearable drug-delivery devices that can be customized to blend directly with the complex, curvilinear and personalized anatomy of patients require materials that are flexible, stretchable, self-healable, tough and moldable. Herein, we have developed such biomaterials from biocompatible and naturally derived compounds, namely PVA and TA. Notably, our unique composition also exhibits high anti-inflammatory and anti-bacterial properties. These attributes, together with its excellent drugloading capacity, make it an ideal candidate for personalized drug-delivery devices.

Despite the fact that many previous studies have combined PVA with TA to produce materials with self-healing, ${ }^{46}$ mechanical, ${ }^{17,47,48}$ anti-bacterial $^{19,49}$ and anti-inflammatory properties, none of the existing PVA and TA biomaterial systems encompass the wide range of properties that PATA does. Indeed, our PATA biomaterial incorporates all of the requested properties mentioned above, including excellent stretchability and high moldability (Fig. 1). This novelty, in combination with the innovative methodology outlined for personalized and wearable drug-delivery devices, renders PATA a unique biomaterial, which holds strong promise in biomedicine. But what was the key to unleashing the hitherto secret powers of PATA? In the following paragraphs we will highlight the mechanistic pathways underlying the remarkable mechanical and self-healing properties of PATA before switching focus to its fascinating biological properties.

The starting point of this story is in the midst of nature; as nature has it's own way of developing materials with mechanical properties similar to the ones encompassed by PATA. For instance, natural materials such as nacre, bone, wood, bamboo and spider-silk owe their unique properties due to tight and hierarchical orchestration of their bonding strengths and architectural complexities at different length scales. ${ }^{8,10,11,50,51}$ Spider silk, for instance, is a hierarchical material dominated by crystalline, rigid and "hard-to-break" domains and weaker hydrogen bonds linking its amorphous regions together. ${ }^{51}$ Bone is another example of such a hierarchical organization, since it consists of a soft and collagenous phase dominated by weak intermolecular links and a hard and crystalline dispersed mineral phase. ${ }^{11}$ As a load is applied, the reversible and sacrificial bonds on the molecular scale dissipate the applied energy to enable such materials to resist more and more loading. Our hypothesis is that a similar mode of action is giving rise to the high stretchability and mechanical toughness of PATA.

Indeed, based on the DSC results shown in Fig. 2, it is clear that PATA is a semi-crystalline polymer with a melting enthalpy $(\Delta H)$ of $84.76\left(\mathrm{~J} \mathrm{~g}^{-1}\right)$. Because the $\Delta H$ value for $100 \%$ crystalline PVA is $138.6\left(\mathrm{~J} \mathrm{~g}^{-1}\right) ;{ }^{29,52}$ we speculate that PATA exhibits a crystallinity degree of $61 \%$. From the observed low $\Delta H$ value of PVA $\left(9.50 \mathrm{~J} \mathrm{~g}^{-1}\right)$, we also speculate that the PATA crystallinity is much larger than that of PVA and increases with the incorporation of TA. A similar trend was observed by Guan et al. These authors found that PVA crystallinity increased to almost $52 \%$ due to the incorporation of TA. ${ }^{47}$ Guan et al. argued that the hydrogen bond networking between PVA and TA improved the ordering of the PVA polymer to give rise to this higher crystallinity. Moreover, the FTIR spectra shown in Fig. 2 also revealed evidence for a hierarchical hydrogen bonding scheme consisting of $\mathrm{OH}-$ $\mathrm{C}=\mathrm{O}\left(7.4 \mathrm{kcal} \mathrm{mol}^{-1}\right)$ and $\mathrm{OH}-\mathrm{OH}\left(4.7 \mathrm{kcal} \mathrm{mol}^{-1}\right)$ with the bonding strength of the first bond being almost two-fold larger than that of the other. ${ }^{53}$ This result, in combination with the physical entanglements between PVA itself, gives rise to four different mechanical contributors to structural integrity and material strength. Altogether, these properties result in a wide range of bonding types with different binding energies. In this scenario, the more strongly bonded PATA domains will keep the system intact as more strain is applied, and the weaker hydrogen bonds will dissipate the loaded energy in a reversible and continuous manner. This situation not only gives rise to high stretchability and material toughness but also self-healing properties, as evidenced by a number of recent studies. $6,13,14,38,54-57$

For instance, Zhang et al. developed a PVA-poly(ethylene glycol) PEG material with high self-healing, toughness and stretchability (400\%), ${ }^{56}$ and speculated that these mechanical properties were due to a similar hierarchical scheme consisting of weak hydrogen bonds, chemical bonds and rigid crystalline regions within PVA. Other studies have shown that the combination of strong covalent and weak ionic bonds within an alginate-polyacrylamide matrix ${ }^{57}$ as well as reversible metal coordination bonds mediated by $\mathrm{Fe}^{3+}$ incorporation into PDMS could yield high stretchability of up to $10000 \%{ }^{4}$ Even so; this value is nowhere near the $30000 \%$ reported in this study.

This discrepancy between previous literature and our current results raises the question why PATA is the first PVA-TA biomaterial that displays such remarkable properties. Firstly, most of the PVA-TA biomaterials reported thus far have been thin films or hydrogels in the conventional sense, which do not display the gum-like characteristics that our PATA does. We believe that this situation arises from the manufacturing methods used so far. These methods typically rely on either a freeze/thawing ${ }^{16,48}$ or solvent casting methodology. ${ }^{47}$ In this study, we used high concentrations of TA (50\%) to form a gum-like substance with hydrogel-like characteristics using a simple mixing procedure with PVA instead. We believe that the key towards this different behavior relates to the high TA concentrations employed in our study, since previous reports on PATA biomaterials used TA concentrations (w/v \%) ranging from $0.16-10 \%$. These values were too low to facilitate spontaneous and homogenous hydrogel formation. The high concentration of TA used in this study also resulted in a significant amount of non-bound TA within PATA, which subsequently could be released in a sustainable manner to yield a drug-like carrier. Indeed, one can also argue that such "free-moving" TA molecules could act as self-healing agents that could remedy material defects quickly and in an on-demand manner. This situation may also be one of the key factors behind the good self-healing capacity of PATA and why a stretchability of $30000 \%$ was attained. 
TA is also widely recognized for its antibacterial properties, ${ }^{19,58}$ which is speculated to arise from various mechanisms including destabilization of the bacterial cytoplasmic membrane, an increase in membrane permeability and TA ability to negatively interact with a number of bacterial proteins. ${ }^{59,60}$ This has prompted its usage to improve the performance of a number of hydrogel-based wound dressings. ${ }^{18,19,58,61}$ For this reason, one of our working hypotheses was that PATA-because it contains TA-could display such antibacterial activities as well. To this end, our in vitro antibacterial tests with PATA included $S$. aureus, one of the primary opportunistic strains of bacteria responsible for causing various types of infections in humans. ${ }^{62,63}$ Interestingly, PATA exhibited a strong response against this specific bacteria and almost completely eliminated its growth after only 4 hours as evidenced by photographic images, inhibition zone characterization and SEM imaging (Fig. 6a-c).

Antibiotics are unequivocally one of the most recognized antibacterial agents by both the broader populace and those working within the field of medicine. Unfortunately, they also come with a number of adverse effects, and over the recent decades a growing number of bacteria types have begun to show some resistance against antibiotics. Other safer alternatives for humanity are based on various metal-based nanoparticles with silver being the most promising and frequently used one. ${ }^{64-66}$ However, some of these nanoparticles are toxic to the human body; others such as silver are too expensive. TA was also erroneously considered as a human toxicant due to some studies in the early 1940s that raised concerns over its hepatotoxic effects. However, more recent studies have come to the conclusion that these effects most likely stemmed from pathophysiological-based effects. ${ }^{67}$ Indeed, numerous studies have recently demonstrated that TA-based cell cytotoxicity is either non-existent or nonprominent under the right conditions. ${ }^{24,58,61}$ We observed the same trend in our cell viability studies in response to TA released from PATA (Fig. 7e). Notably, our results demonstrated high cell viability for three different epithelial cell types, i.e. primary, Caco-2 and CAL-17 epithelial cells. Therefore, the once-feared TA cytotoxicity is slowly taking the shape as an urban legend in the biomedical community. This fact, in combination with the cheap and abundant nature of TA, renders it a suitable alternative to some of the aforementioned "state-of-the-art" antibacterial agents in the field.

Additionally, TA is also known to possess antioxidant and anti-inflammatory properties like many other polyphenolic compounds "out there". ${ }^{6,69}$ TA released from PATA displayed similar anti-inflammatory properties, as it could reduce the production of cytokines from LPS activated macrophages to a substantial degree (Fig. 7d). In combination with doxepin it was also found that TA significantly reduced chemotherapy-induced cell apoptosis. This effect is most likely caused by the antioxidant and anti-scavenging capacity of TA, which in turn may enable it to perform its anti-oxidant and anti-inflammatory properties on the epithelial cells that have been damaged by chemotherapy to prevent them from entering apoptosis. ${ }^{70-72}$

Overall, the unique combination of properties that PATA exhibits renders it an ideal drug-delivery carrier to be used in personalized wearables such as the mucositis-targeting drugdelivery device developed in this study (Fig. 7). We envision that the approach outlined here could potentially carve out an exciting pathway for the on-site and on-demand production of a wide range of drug-delivery devices that can be customized to meld directly with a patient's anatomy. Advantageously, the methodology proposed here could significantly reduce both waiting time for surgery and the associated patient healthcare costs.

\section{Conclusion}

We have used a cheap, scalable, ecofriendly and simple "design and mixing" procedure to create a novel biomaterial (referred to as PATA) with a unique combination of mechanical, selfhealing and biological properties. We demonstrated that it is displays anti-bacterial and anti-inflammatory properties along with an excellent self-healing capacity, flexibility, stretchability and moldability. The group of materials to which PATA belongs can be termed "human-friendly" because they share many features with human tissues. We also argued and demonstrated that such materials are necessary to make wearables that can readily integrate with the curved, flexible, complex and personalized anatomy of a patient. Finally, we demonstrated that PATA encompass hydrogellike properties, which facilitate excellent control over drug delivery kinetics. Overall, the proof-of-concept methodology outlined here may open up a new avenue in the pursuit of advanced functional materials for the wearables industry and within the field of personalized medicine.

\section{Experimental section}

\section{Preparation of the PATA biomaterial}

The formation of PATA was initiated by dissolving $10 \mathrm{~g}$ of TA (Sigma-Aldrich) in $20 \mathrm{ml}$ of PBS ( $\mathrm{pH} \mathrm{7.4)} \mathrm{to} \mathrm{obtain} \mathrm{a} 50 \% \mathrm{w} / \mathrm{v}$ solution. In addition, a solution of PVA $\left(M_{\mathrm{w}} 31000-48000\right.$; $10 \% \mathrm{w} / \mathrm{v}$ in PBS; pH 7.4) was prepared in another glass bottle through the constant stirring at $50{ }^{\circ} \mathrm{C}$ for $5 \mathrm{~h}$. To form the hydrogel, $12 \mathrm{ml}$ of $10 \%$ PVA solution was placed into a $50 \mathrm{ml}$ falcon tube and $2 \mathrm{ml}$ of TA $(50 \% \mathrm{w} / \mathrm{v})$ was added stepwise under vigorous vortexing, followed by mixing with spatula for 1 minute. The hydrogel was then washed and stored in Milli-Q water at room temperature for further usage.

\section{Molecular structure and thermal analyses}

The molecular structure of the PATA hydrogels was investigated by Attenuated total reflectance-Fourier transform infrared (ATRFTIR) using a PerkinElmer Spectrum 100 FTIR spectrometer (USA) equipped with a diamond crystal attenuated total reflectance (ATR) accessory after background subtraction ATR sampling accessory. PATA hydrogel was freeze-dried and grinded into powder prior to each measurement to identify the occurring interactions between PVA and TA. The wavenumber region of $4000-500 \mathrm{~cm}^{-1}$ was used to record the spectra with 16 scans at a resolution of $4 \mathrm{~cm}^{-1}$. All spectra were baseline corrected and normalized using the PerkinElmer Spectrum software. 
Differential Scanning Calorimetry (DSC) was used to estimate the crystallinity and stability of the hydrogel. For the DSC measurements, grinded samples were pre-dried in oven for $30 \mathrm{~min}$ at $60{ }^{\circ} \mathrm{C}$ and $12 \mathrm{~h}$ at $37{ }^{\circ} \mathrm{C}$. Then $5 \mathrm{mg}$ of samples was placed in $30 \mu \mathrm{l}$ aluminum pans and sealed. Samples were equilibrate at $25{ }^{\circ} \mathrm{C}$ and measurements were performed from 25 to $300{ }^{\circ} \mathrm{C}$ under continuous $50 \mathrm{ml} \mathrm{min}{ }^{-1} \mathrm{~N}_{2}$ purge gas flow and an accelerating heating rate of $10{ }^{\circ} \mathrm{C} \mathrm{min}^{-1}$. The thermal analysis experiments were performed on TA Instruments DSC Q200 at least in triplicate.

The thermal stability of the hydrogel was determined by thermogravimetric analysis (TGA) using TA TGA Q500 Thermogravimetric Analyzer. The thermogravimetry measurements on freeze-dried samples were carried out under continuous $\mathrm{N}_{2}$ flow $\left(60 \mathrm{ml} \mathrm{min}{ }^{-1}\right)$. The temperature scan rate was $10{ }^{\circ} \mathrm{C} \mathrm{min}^{-1}$ from 30 to $800{ }^{\circ} \mathrm{C}$.

\section{Water content, swelling, retention ration and weight loss studies}

Water content and swelling studies were performed for various types of PATA hydrogels prepared through the interaction of PVA solution in PBS buffer ( $\mathrm{pH}$ 7.4) and TA dissolved in different solutions (Milli-Q water, $\mathrm{PBS} \mathrm{pH}$ 7.4, and $\mathrm{NaOH}$ with various molarities). The water content was measured using the below formula:

$$
\text { Water content }(\%)=\frac{W_{\mathrm{w}}-D_{\mathrm{w}}}{W_{\mathrm{w}}}
$$

where $W_{\mathrm{w}}$ and $D_{\mathrm{w}}$ are wet weight and dry weight of the hydrogel, respectively.

To measure the swelling ratio, all above-mentioned hydrogels were first dried in the oven at $40{ }^{\circ} \mathrm{C}$ for $72 \mathrm{~h}$. Next, the samples were immersed in the PBS buffer $(\mathrm{pH} 7.4)$ and the swelling ratio was calculated as a function of time using eqn (2) through the measurement of wet weight $\left(M_{\mathrm{w}}\right)$ and dry weight $\left(M_{\mathrm{d}}\right)$ at the respective time points. Swelling was allowed to continue until an equilibrium swelling state was reached, i.e. sample weight remained constant. Before a sample was weighed, water in the surface of the hydrogel was gently removed with filter paper. At least three samples were studied for each time point and an average was calculated.

$$
\text { Swelling ratio }=\frac{M_{\mathrm{w}}-M_{\mathrm{d}}}{M_{\mathrm{d}}}
$$

After swelling for $24 \mathrm{~h}$, which was an equilibrium point, the samples were removed from the PBS buffer and left at room temperature in dry condition for 10 days to evaluate the water retention ratio by the same formula used for the calculation of swelling ratio.

To assess the rate of weight loss, which can be an indicator of degradation or component release from the hydrogels, the sample was first prepared using PVA and TA both dissolved in PBS (pH 7.4) as the optimal condition and then dried and weighted. Next, the hydrogels were incubated in PBS ( $\mathrm{pH} 7.4$ and 6.8) at $37^{\circ} \mathrm{C}$. At each time point of $1,2,4,8$, and $24 \mathrm{~h}$, three replicates of the hydrogels were removed from the medium and dried. The weight loss (\%) was then calculated using eqn (3), where the difference of initial dried mass before adding the samples to the PBS buffer (initial $M_{\mathrm{w}}$ ) and the dried mass of the same samples at each time point post-immersion into the buffer $\left(M_{\mathrm{w}}(t)\right)$ was divided by its measured initial dried weight. Each combination was replicated 3 times to get an average value of the weight loss (\%).

$$
\text { Weight loss }(\%)=\frac{\text { Initial } M_{\mathrm{w}}-M_{\mathrm{w}}(t)}{\text { Initial } M_{\mathrm{w}}} \times 100
$$

\section{Mechanical characterization}

The mechanical properties of the hydrogels were analyzed using an Instron (Model 5967, UK) mechanical tester equipped with a $500 \mathrm{~N}$ load cell, under tensile mode with an initial grip separation of $2 \mathrm{~mm}$ and crosshead speed of $100 \mathrm{~mm} \mathrm{~min}^{-1}$. Tensile properties, elastic modulus, toughness, and recycling efficiency were measured for individually prepared hydrogels in six replicates. Prior to the test, the length, width, and thickness of the hydrogels were adjusted to $22 \mathrm{~mm}, 14 \mathrm{~mm}$, and $1 \mathrm{~mm}$, respectively, using a Vernier caliper. The toughness was estimated as the area under the stress-strain curve, while recycling efficiency (\%) was calculated as the ratio of toughness in $N$ and $N-1$ recovery cycle (eqn (4)):

$$
\text { Recycling efficiency }(\%)=\frac{\text { Toughness }(\text { Cycle } N)}{\text { Toughness }(\text { Cycle } N-1)} \times 100
$$

Prior to mechanical testing, all samples were allowed to swell in Milli-Q water for $24 \mathrm{~h}$. Mechanical properties were investigated in different conditions, including (1) after hydrogel formation; (2) every $2 \mathrm{~h}$ for up to 8 hours for each individual sample; (3) after tannic acid release from the hydrogel in PBS ( $\mathrm{pH}$ 7.4) by changing the release media every $24 \mathrm{~h}$ (shown as $72 \mathrm{~h}$ in the figures); (4) after drying the samples and soaking in PBS ( $\mathrm{pH} 7.4)$ for different time intervals ( 0.5 h, 1 h, 2 h, 3 h, 4 h, 8 h, 24 h); (5) and every 2 h for up to 8 hours for drug loaded PATA hydrogels. Specimens were placed in Milli-Q water during the $2 \mathrm{~h}$ intervals of cycles.

\section{Self-healing behavior of the PATA hydrogel}

Macroscopic self-healing property of the hydrogel was evaluated visually by screening of the gel recovery after cutting the colored gels into small separated pieces with a surgical knife and observing their fusion without the application of a continuous external pressure. Red and green food colors were loaded into the gels as staining agents for better visualization. The healing behavior, stretchability, and moldability were visually observed for the fused gels of different colors. Moreover, the mechanical properties of a PATA hydrogel with the length of $22 \mathrm{~mm}$, width of $14 \mathrm{~mm}$, and thickness of $1 \mathrm{~mm}$ were studied after cutting it and putting separated pieces next to each other for $4 \mathrm{~min}$. In addition, the central section of a cubic hydrogel was cut off, and then the separated pieces were put together under an optical microscopy without any external pressure at room temperature to record the self-healing process of the hydrogel over time. The SEM imaging of the healing zone was also obtained after putting the separated zones together for $4 \mathrm{~min}$. 


\section{DPPH $^{\bullet}$ free radical scavenging activity}

To measure the scavenging activity of the gels, the bleaching rate of a stable free radical, $\mathrm{DPPH}^{\bullet}$, was monitored in the presence of TA released from the gel. For this purpose, $600 \mathrm{mg}$ of the PATA gel was placed in $100 \mathrm{ml}$ of PBS, pH 7.4 and 6.8, separately. At different time points $(15 \mathrm{~min}, 30 \mathrm{~min}$, $90 \mathrm{~min}, 240 \mathrm{~min}, 480 \mathrm{~min}$ ), $200 \mu \mathrm{l}$ of the PBS medium was withdrawn and added to glass bottle for drying at $37{ }^{\circ} \mathrm{C}$ overnight. Next, $1.5 \mathrm{ml}$ of ethanol was added to the glass bottles containing dried TA released from the gel, vortexed for $2 \mathrm{~min}$ and allowed to stand for $20 \mathrm{~min}$. Afterwards, $0.5 \mathrm{ml}$ of $\mathrm{DPPH}^{\bullet}$ solution $(0.1 \mathrm{mM})$ prepared in ethanol was added to glass bottles. The mixture was vigorously vortexed and incubated in dark for $30 \mathrm{~min}$ before measuring the absorbance at $517 \mathrm{~nm}$ against control samples which were prepared as above without having the PATA gel within the releasing media of PBS. Ethanol was used for the baseline correction. In its radical form, $\mathrm{DPPH}^{\bullet}$ absorbs at $517 \mathrm{~nm}$, but its absorption decreases upon reduction by an antioxidant. Therefore, the lower absorbance of the reaction mixture is an indicative of higher radical scavenging activity. Radical scavenging effect was expressed as percentage, calculated by the following equation:

$$
\mathrm{DPPH}^{\bullet} \text { scavenging effect }(\%)=\left(1-\frac{A_{\mathrm{s}}}{A_{\mathrm{c}}}\right) \times 100
$$

where, $A_{\mathrm{s}}$ is the absorbance in the presence of tannic acid released from the gel and $A_{\mathrm{c}}$ is the absorbance of the control which contains DPPH${ }^{\bullet}$ solution. The same study was performed for the free TA and $\alpha$-tocopherol at various known concentrations $\left(10,20,30\right.$, and $40 \mu \mathrm{g} \mathrm{ml} \mathrm{m}^{-1}$; results shown in the ESI $\left.\dagger\right)$.

\section{Total antioxidant activity assay by $\mathrm{ABTS}^{\bullet+}$ radical cation decolorization assay}

The ABTS $^{\bullet+}$ method is based on the ability of antioxidants to quench the long-lived ABTS radical cation, a blue/green chromophore with characteristic absorption at $734 \mathrm{~nm}$. For this purpose, $600 \mathrm{mg}$ of the PATA gel was placed in $100 \mathrm{ml}$ of PBS with the $\mathrm{pH}$ values of 7.4 and 6.8, separately. At different time points (15 min, $30 \mathrm{~min}, 90 \mathrm{~min}, 240 \mathrm{~min}, 480 \mathrm{~min}$ ), $200 \mu \mathrm{l}$ of the PBS medium was withdrawn and added to glass bottle for drying at $37{ }^{\circ} \mathrm{C}$ overnight. The dried TA samples were then dissolved in $3 \mathrm{ml}$ of ethanol. Next, $\mathrm{ABTS}^{\bullet+}$ was produced by reacting $2 \mathrm{mM}$ ABTS in $\mathrm{H}_{2} \mathrm{O}$ with $2.45 \mathrm{mM}$ potassium persulfate and allowing the mixture to stand in the dark at room temperature for four hours. The ABTS ${ }^{\bullet+}$ solution was diluted in sodium phosphate buffer $(0.1 \mathrm{M}, \mathrm{pH} 7.4)$ to get an absorbance of $0.750 \pm 0.023$ at $734 \mathrm{~nm}$. Next, $1 \mathrm{ml}$ of diluted $\mathrm{ABTS}^{\bullet+}$ solution was added to as-prepared $3 \mathrm{ml}$ ethanol solution of TA released from the gel. After $30 \mathrm{~min}$, the percentage inhibition of $\mathrm{ABTS}^{\bullet+}$ at $734 \mathrm{~nm}$ was calculated relative to a control by measuring the extent of decolorization using the below equation:

$$
\mathrm{ABTS}^{\bullet+} \text { scavenging effect }(\%)=\left(1-\frac{A_{\mathrm{s}}}{A_{\mathrm{c}}}\right) \times 100
$$

where, $A_{\mathrm{s}}$ is the absorbance of the remaining concentration of $\mathrm{ABTS}^{\bullet+}$ in the presence of tannic acid released from the gel and
$A_{\mathrm{c}}$ is the absorbance of the initial concentration of the $\mathrm{ABTS}^{\bullet+}$ in the absence of TA released from the gel. The same study was performed for the free TA and $\alpha$-tocopherol at various known concentrations $\left(10,20,30\right.$, and $40 \mu \mathrm{g} \mathrm{ml}^{-1}$; results shown in the ESI $\left.\dagger\right)$.

\section{Reducing power assay of PATA gel}

In this experiment, $600 \mathrm{mg}$ of the gel was first placed within $100 \mathrm{ml}$ of PBS buffers with the pHs of 7.4 and 6.8, separately. At different time points $(15 \mathrm{~min}, 30 \mathrm{~min}, 90 \mathrm{~min}, 240 \mathrm{~min}$, $480 \mathrm{~min}$ ), $200 \mu \mathrm{l}$ of the supernatant was withdrawn and mixed with $800 \mu \mathrm{l}$ of phosphate buffer in a falcon tube. Next, $5 \mathrm{ml}$ of $0.2 \mathrm{M}$ phosphate buffer ( $\mathrm{pH} 6.6$ ) and $5 \mathrm{ml}$ of $1 \%$ potassium ferricyanide solution were added and the mixture was incubated at $50{ }^{\circ} \mathrm{C}$ for $20 \mathrm{~min}$. Afterwards, $5 \mathrm{ml}$ of trichloroacetic acid $(10 \%)$ was added and the content was centrifuged at $1000 \mathrm{rpm}$ for $10 \mathrm{~min}$. The upper layer of the supernatant $(5 \mathrm{ml})$ was then withdrawn and mixed with $5 \mathrm{ml}$ of distilled water and $1 \mathrm{ml}$ of $\mathrm{FeCl}_{3}(0.1 \%)$ under vortex. The absorbance against water blank was measured using a spectrophotometer at $700 \mathrm{~nm}$. Increased absorbance of the reaction mixture is an indicative of enhanced reduction capability. All the experiments were performed in triplicates. The same study was performed for the known concentrations of TA $\left(20,40,60,80,100\right.$, and $120 \mu \mathrm{g} \mathrm{ml} \mathrm{m}^{-1}$; results shown in the $\mathrm{ESI} \dagger)$.

\section{Effect of released TA on reactive oxygen species (ROS) inhibition in $\mathrm{J} 774$ macrophages}

The inhibition of ROS production was studied on J774 cells. These cells were cultured in Roswell Park Memorial Institute medium (RPMI) 1640 media, which was supplemented with $10 \%$ fetal bovine serum and 1\% penicillin and streptomycin. Cells were grown in $75 \mathrm{~cm}^{2}$ flasks (Corning, MA, USA) at $37{ }^{\circ} \mathrm{C}$ in a mixture of $5 \% \mathrm{CO}_{2}$ and $95 \%$ air atmosphere. To evaluate the effect of released TA on ROS generation, 25000 per well of J774 cells were seeded in a 96 well plate (Nunc, Denmark) and allowed to adhere for $24 \mathrm{~h}$. The cells were then washed once with Dulbecco's Phosphate buffer saline (DPBS) before incubating with $200 \mu \mathrm{l}$ of $10 \mathrm{mM}$ solution of $2^{\prime}, 7^{\prime}$-dichlorodihydrofluorescein diacetate for $1 \mathrm{~h}$ at $37{ }^{\circ} \mathrm{C}$. Then, the cells were washed once and incubated with $100 \mu \mathrm{l}$ of TA released from $600 \mathrm{mg}$ of dried hydrogel in PBS (pH 6.8 and $\mathrm{pH}$ 7.4) at different time points $(15,30,60,240$ and $480 \mathrm{~min})$ for $2 \mathrm{~h}$. After the incubation period, $100 \mu \mathrm{l}$ of $0.03 \%$ hydrogen peroxide solution were added to each well and the microplate was incubated for $30 \mathrm{~min}$ at $37^{\circ} \mathrm{C}$. The UV absorbance of the wells was then read at excitation and emission wavelengths of 498 and $522 \mathrm{~nm}$, respectively. Triplicate measurement was performed for each sample.

\section{Doxepin loading in PATA gel}

For the loading of doxepin in PATA gel, $100 \mathrm{mg}$ of doxepin was dissolved in $3 \mathrm{ml}$ of PVA solution $\left(0.1 \mathrm{~g} \mathrm{ml}^{-1}\right)$. Then, $0.5 \mathrm{ml}$ of TA solution $\left(0.5 \mathrm{~g} \mathrm{l}^{-1}\right)$ was added dropwise to the doxepin and PVA solution under continuous vortex. The solutions were vortex for $60 \mathrm{~s}$, following by manual mixing with a glass rod for $60 \mathrm{~s}$. The supernatant of the gel was used to determine the unencapsulated doxepin. The gel was then washed once with 
Milli-Q water and completely dried prior to the release studies. The encapsulation efficiency (EE) was calculated using the following equation:

$$
\begin{aligned}
& \mathrm{EE}(\%)= \\
& \text { Initial drug amount }(\mu \mathrm{g})-\text { Unencapsulated drug amount }(\mu \mathrm{g})
\end{aligned}
$$$$
\text { Initial drug amount }(\mu \mathrm{g})
$$

$$
\times 100
$$

The unencapsulated doxepin was determined using a HPLC instrument (Shimadzu, Japan). A Sunfire C18 column (100 A, $3.5 \mu \mathrm{m}, 4.6 \mathrm{~mm} \times 150 \mathrm{~mm}$; waters, USA) was used at room temperature. The aqueous mobile phase comprised of $0.05 \%(\mathrm{v} / \mathrm{v})$ trifluoroacetic acid (TFA) in water and the organic mobile phase consisted of $0.05 \%(\mathrm{v} / \mathrm{v})$ in acetonitrile. An isocratic system was developed with a ratio of $65: 35(\mathrm{v} / \mathrm{v})$ of aqueous to organic phase at flow rate of $1 \mathrm{ml} \mathrm{min}{ }^{-1}$. The injection volume used was $10 \mu \mathrm{l}$ and the detection wavelength was $215 \mathrm{~nm}$.

\section{Holder formation and in vitro doxepin release studies in simulated saliva fluid}

Doxepin-loaded PATA gel was placed into a holder with an average capacity of $13 \pm 1 \mathrm{mg}$ of the dried gel. As a proof of concept for the development of small fixable devices on the teeth for local drug release in the oral cavity, the holder was fabricated from poly(methyl methacrylate) by laser cutting technology in a dimension of $4 \times 4 \times 2$ milimeter. The gel loaded holder was fixed on the wall of a glass vial $(2.5 \mathrm{~cm}$ above the base of the glass vial) before adding $15 \mathrm{ml}$ of simulated saliva fluid as the release medium. The release study was performed at $37{ }^{\circ} \mathrm{C}$ under gentle stirring of the release medium. $200 \mu \mathrm{l}$ of the medium was withdrawn at each time point, followed by subsequent replacement with fresh pre-warmed release buffer. The samples were then centrifuged at $17860 \times g$ for $5 \mathrm{~min}$ and the supernatant was analyzed using the HPLC method explained in the previous section to quantify doxepin. TA release was quantified by UV-vis method at $245 \mathrm{~nm}$ using a calibration curve. The release study was conducted for seven days in triplicate.

The simulated saliva fluid was composed of sodium chloride 14.4 $\mathrm{mM}$, potassium chloride $16.1 \mathrm{mM}$, calcium chloride dehydrate $1.3 \mathrm{mM}$, magnesium chloride hexahydrate $0.55 \mathrm{mM}$, and dibasic potassium phosphate $2 \mathrm{mM}$. The $\mathrm{pH}$ of the simulated saliva fluid was maintained at $6.8 .^{73,74}$

\section{Inhibition of TNF- $\alpha$ production in J774 macrophages}

The anti-inflammatory activity of the TA released from gel was evaluated in J774 macrophages. For this purpose, $120 \mathrm{mg}$ of the dried gel was added to pre-warmed buffer solution ( $\mathrm{pH} 6.8$ and $\mathrm{pH} 7.4)$ at $37^{\circ} \mathrm{C}$. Then, $300 \mu \mathrm{l}$ of supernatant was withdrawn at each time point $(15,30$, and $240 \mathrm{~min})$ and subsequently replaced with pre-warmed fresh buffer. Afterwards, the withdrawn buffer containing released TA was lyophilized and redispersed in complete cell-culturing medium consisting of $100 \mathrm{ng} \mathrm{ml}^{-1}$ lipopolysaccharides (LPS, Sigma Aldrich). Next, the macrophages were cultured in DMEM medium supplemented with $10 \%$ fetal bovine serum and kept in a standard incubator at $37{ }^{\circ} \mathrm{C}$ in an atmosphere of $5 \% \mathrm{CO}_{2}$ and $95 \%$ relative humidity. For the study, 50000 cells were seeded per well in a 48-well plate and incubated overnight to allow cells to attach. After incubation, the medium was removed from the cells and the LPS solution containing released TA was added to the cells. The cells were also treated with LPS $\left(100 \mathrm{ng} \mathrm{ml}^{-1}\right.$ ) alone as positive control. After incubation for $24 \mathrm{~h}$, the supernatants were collected and centrifuged at $250 \times g$ to remove any cell debris. The cell free supernatants were then analyzed using TNF- $\alpha$ ELISA plates (Invitrogen, USA) following the instruction provided by the manufacture. The results are expressed as fold decrease in TNF- $\alpha$ secretion calculated by the below equation:

Fold decrease in $\mathrm{TNF} \alpha=($ Concentration of $\mathrm{TNF} \alpha$ produced

by cells exposed to LPS)/(Concentration of TNF $\alpha$ produced

by cells exposed to LPS and released TA)

\section{Viability assay}

For the toxicity assay, 96 well plates were used. In each well, $25 \times 10^{3}$ cells were placed and left in the incubator overnight. After cell attachment, media in the wells were replaced and different amounts of the freeze-dried hydrogel were added in three repetitions. Control group was only exposed to the medium. The experiment was performed at two different $\mathrm{pH}$ values, 7.4 and 6.8. After $24 \mathrm{~h}$ of treatment, medium was removed and $200 \mu \mathrm{l}$ of the phenol red free DMEM was added along with $10 \mu \mathrm{l}$ of WST-1 solution. After 4 hours of incubation at $37{ }^{\circ} \mathrm{C}$, absorbance values of all wells were read at $440 \mathrm{~nm}$ using an ELISA plate reader. The viable cells produce yellow color in WST-1 toxicity test, while dead cells cause no color formation in the wells. Three different cell lines including, primary epithelial cells, Caco-2 epithelial cells, and CAL 27 epithelial cells.

\section{Anti-mucositis effect of drug loaded PATA gel through apoptosis assay}

To assess chemotherapy-induced apoptosis, $1.5 \times 10^{5}$ primary epithelial cells were cultured on poly-L-lysine coated coverslips placed in the lower compartment of a 24 Transwell permeable plates (Corning $\left.{ }^{\mathbb{R}}\right)$. Dulbecco's Modified Eagle's Medium (DMEM) supplemented with $10 \%$ fetal bovine serum, $30 \mathrm{U} \mathrm{ml}^{-1}$ penicillin, and $30 \mathrm{mg} \mathrm{ml}^{-1}$ streptomycin was used for the culturing purpose. After incubation at $37{ }^{\circ} \mathrm{C}$ and under $5 \% \mathrm{CO}_{2}$ for $24 \mathrm{~h}$, the drug loaded gel was added into the upper compartment. The wells were left then for $1 \mathrm{~h}$ to allow the sustain release of the drug and TA from the gel. Afterwards, $100 \mu \mathrm{l}$ of a stock solution of 5-Fluorouracil (5-FU) in DMEM was added to the wells to get a final concentration of $10 \mu \mathrm{M}$ of 5-FU in each well for the induction of apoptosis. After $24 \mathrm{~h}$ of incubation at $37^{\circ} \mathrm{C}$, the cells were washed gently with PBS (pH 7.4) for three times and cell apoptosis was evaluated using the DeadEnd ${ }^{\mathrm{TM}}$ Fluorometric TUNEL assay (Promega Corp.) according to the manufacturer's instruction. TUNEL-positive cells were analyzed using a fluorescence microscope (Carl Zeiss, Germany). Samples exposed to both the gel and 5-FU were compared to the cells only treated with 5-FU in the absence of the gel. Control group received no exposure to the gel or 5-FU. 


\section{Antibacterial effect of the PATA hydrogel}

Since the risk of bacterial infection is very high in patients suffering from mucositis, the inhibitory effect of the TA released from the gel was evaluated on the Gram-positive bacteria, S. aureus. First, $600 \mathrm{mg}$ of the freshly prepared PATA gel was placed in $100 \mathrm{ml}$ of PBS, pH 7.4 and 6.8, separately. At different time points $(1 \mathrm{~h}, 4 \mathrm{~h}, 8 \mathrm{~h}$, and $24 \mathrm{~h}), 1 \mathrm{ml}$ of the buffer was withdrawn and added to $4 \mathrm{ml}$ of PBS buffer $\left(\mathrm{pH} 7.4 ; 37^{\circ} \mathrm{C}\right)$ containing approximately $3 \times 10^{4} \mathrm{CFU}$ of the bacteria. The samples were incubated for $24 \mathrm{~h}$ at $37{ }^{\circ} \mathrm{C}$ after which $75 \mu \mathrm{l}$ of the suspension was taken out and cultured on the agar plate using disposable spreaders. The culturing plates were then left in incubator at $37^{\circ} \mathrm{C}$ overnight before visualizing the TA effect on the bacterial survival and proliferation. In the control group, the buffer containing bacterial received $1 \mathrm{ml}$ of PBS (pH 7.4) instead of the TA released from the gel. The morphology and change in the rate of bacterial survival were further observed by SEM using a QUANTA 200 (Philips-FEI, Holland). Bacterial suspension $\left(3 \times 10^{4} \mathrm{CFU}\right.$ in $\left.4 \mathrm{ml}\right)$ treated with $1 \mathrm{ml}$ of TA released from the gel at different time points ( $1 \mathrm{~h}$ and $24 \mathrm{~h}$ ) were incubated for $24 \mathrm{~h}$ at $37{ }^{\circ} \mathrm{C}$. Then, the samples were centrifuged for bacterial separation before fixation with glutaraldehyde $(2.5 \%)$ for $3 \mathrm{~h}$ and serial dehydration using ethanol (20-100\%; $30 \mathrm{~min}$ each). In the last step, the samples were added to double-sided adhesive carbon tapes placed on SEM stubs and allowed to dry for SEM analysis.

Agar disc diffusion method was also conducted. In this experiment, the concentration of the bacteria was adjusted to nearly $100 \times 10^{5} \mathrm{CFU}$ per $\mathrm{ml}$. Then, $100 \mu \mathrm{l}$ of the microorganism suspension was spreaded on an agar plate before placing $9 \mathrm{~mm}$ sterile paper discs on the agar plate and adding $60 \mu \mathrm{l}$ of the release buffers (pH 7.4 and pH 6.8) at various time points ( 84 h, 8 h, 24 h). The plate was incubated at $37^{\circ} \mathrm{C}$ for $18 \mathrm{~h}$ and then the inhibition zone of microorganism growth was determined as the diameter of the clean zone around the disc. The tests were performed in triplicate for each time point of TA release.

\section{Conflicts of interest}

There are no conflicts to declare.

\section{Authorship contribution statement}

M.-A. S.: Idea development; design of the work; conducting majority of experiments, such as physicochemical characterizations and optimizations, antibacterial and cellular assays, anti-scavenging study, holder fabrication, and self-healing assay; contribution in the experiments performed by co-authors, such as mechanical studies; providing resources for raw material purchase as well as antibacterial and cellular studies; data analysis and interpretation; involvement in the writing process. N. S. and V. P.: Performing doxepin loading and protocol and instrumental set up for drug measurements; providing resources and budget for drug loading, release, antioxidant, and anti-inflammatory studies; drug loading assay; hydrogel fabrication and performing release, antioxidant, and anti-inflammatory studies; analysis of release, antioxidant, and anti-inflammatory data; involved in final manuscript editing process. M. K. P.: Sample preparation and involvement in FTIR, DSC, TGA, DTG, and mechanical studies; contribution in getting self-healing images; involved in result discussion and preparation of figures for the manuscript. F. B. K.: Contributing in performing and analysis of mechanical studies and FTIR experiments, involved in the interpretation of results, and writing the chemical characterization section. M. M.: Data analysis; performing the DSC experiment; involved in result discussion. M. H.: Contribution to the mechanical experiments; analysis of experimental data; contributing in the preparation of main and supplementary figures; involved in designing studies related to physicochemical characterization and result discussion. S. L.: Help with manuscript writing, editing and discussion of results. A. D.-P.: Providing resources for equipment, and experiment conduction; project supervision; result discussion; providing scientific advice during the work, manuscript writing and editing.

\section{Acknowledgements}

ADP would like to acknowledge the Danish Council for Independent Research (Technology and Production Sciences, 5054-00142B), Gigtforeningen (R139-A3864), the Villum Foundation (10103) and the VIDI research programme with project number R0004387, which is (partly) financed by the Netherlands Organisation for Scientific Research (NWO). M.-A. S. acknowledges financial support from Iran's National Elites Foundation. N. S. would like to acknowledge funding from the European Union's Horizon 2020 Research and Innovation Programme under the Marie Sklodowska-Curie grant agreement number 751257.

\section{Notes and references}

1 M. Mehrali, S. Bagherifard, M. Akbari, A. Thakur, B. Mirani, M. Mehrali, M. Hasany, G. Orive, P. Das, J. Emneus, T. L. Andresen and A. Dolatshahi-Pirouz, Adv. Sci., 2018, 5, 1870059.

2 F. B. Kadumudi, M. Jahanshahi, M. Mehrali, T. G. Zsurzsan, N. Taebnia, M. Hasany, S. Mohanty, A. Knott, B. Godau, M. Akbari and A. Dolatshahi-Pirouz, Adv. Sci., 2019, 6, 1801241.

3 D.-H. Kim, N. Lu, R. Ma, Y.-S. Kim, R.-H. Kim, S. Wang, J. Wu, S. M. Won, H. Tao and A. Islam, Science, 2011, 333, 838-843.

4 C.-H. Li, C. Wang, C. Keplinger, J.-L. Zuo, L. Jin, Y. Sun, P. Zheng, Y. Cao, F. Lissel and C. Linder, Nat. Chem., 2016, 8, 618.

5 M. Mehrali, A. R. Akhiani, S. Talebian, M. Mehrali, S. T. Latibari, A. Dolatshahi-Pirouz and H. S. C. Metselaar, J. Eur. Ceram. Soc., 2016, 36, 319-332.

6 Y. Wu, D. U. Shah, C. Liu, Z. Yu, J. Liu, X. Ren, M. J. Rowland, C. Abell, M. H. Ramage and O. A. Scherman, Proc. Natl. Acad. Sci. U. S. A., 2017, 114, 8163-8168.

7 M. Mehrali, A. Thakur, C. P. Pennisi, S. Talebian, A. Arpanaei, M. Nikkhah and A. Dolatshahi-Pirouz, Adv. Mater., 2017, 29, 1603612. 
8 R. O. Ritchie, Nat. Mater., 2011, 10, 817.

9 A. Thakur, M. K. Jaiswal, C. W. Peak, J. K. Carrow, J. Gentry, A. Dolatshahi-Pirouz and A. K. Gaharwar, Nanoscale, 2016, 8, 12362-12372.

10 H. Zhu, S. Zhu, Z. Jia, S. Parvinian, Y. Li, O. Vaaland, L. Hu and T. Li, Proc. Natl. Acad. Sci. U. S. A., 2015, 112, 8971-8976.

11 U. G. K. Wegst, H. Bai, E. Saiz, A. P. Tomsia and R. O. Ritchie, Nat. Mater., 2015, 14, 23.

12 X. Zhao, Proc. Natl. Acad. Sci. U. S. A., 2017, 114, 8138-8140.

13 T. Yuan, X. Cui, X. Liu, X. Qu and J. Sun, Macromolecules, 2019, 52, 3141-3149.

14 X. Fang and J. Sun, ACS Macro Lett., 2019, 8, 500-505.

15 Y. Takemoto, H. Ajiro and M. Akashi, Langmuir, 2015, 31, 6863-6869.

16 H. Zhang, H. Xia and Y. Zhao, ACS Macro Lett., 2012, 1, 1233-1236.

17 Y.-N. Chen, C. Jiao, Y. Zhao, J. Zhang and H. Wang, ACS Omega, 2018, 3, 11788-11795.

18 M. Sahiner, S. Sagbas and B. O. Bitlisli, J. Appl. Polym. Sci., 2015, 132, 41876.

19 N. Ninan, A. Forget, V. P. Shastri, N. H. Voelcker and A. Blencowe, ACS Appl. Mater. Interfaces, 2016, 8, 28511-28521.

20 M. Rezazadeh, N. Jafari, V. Akbari, M. Amirian, M. Tabbakhian, M. Minaiyan and M. Rostami, Drug Delivery Transl. Res., 2018, 8, 1226-1237.

21 A. E. Abdel Moneim, A. Guerra-Librero, J. Florido, Y.-Q. Shen, B. Fernández-Gil, D. Acuña-Castroviejo and G. Escames, Int. J. Mol. Sci., 2017, 18, 1003.

22 M. G. Drozdova, D. S. Zaytseva-Zotova, R. A. Akasov, A. S. Golunova, A. A. Artyukhov, O. O. Udartseva, E. R. Andreeva, D. E. Lisovyy, M. I. Shtilman and E. A. Markvicheva, Mater. Sci. Eng., C, 2017, 75, 1075-1082.

23 Y. Shirmohammadli, D. Efhamisisi and A. Pizzi, Ind. Crops Prod., 2018, 126, 316-332.

24 S. A. Abouelmagd, F. Meng, B.-K. Kim, H. Hyun and Y. Yeo, ACS Biomater. Sci. Eng., 2016, 2, 2294-2303.

25 J. Aguilera, V. Venegas, J. M. Oliva, M. J. Sayagués, M. de Miguel, J. A. Sánchez-Alcázar, M. Arévalo-Rodríguez and A. Zaderenko, RSC Adv., 2016, 6, 7279-7287.

26 T. Hu, Q. Liu, T. Gao, K. Dong, G. Wei and J. Yao, ACS Omega, 2018, 3, 7523-7531.

27 R.-M. Wang, S.-R. Zheng and Y. G. Zheng, Polymer matrix composites and technology, Elsevier, 2011.

28 O. W. Guirguis and M. T. Moselhey, Nat. Sci., 2012, 4, 57.

29 J. Liang, Y. Huang, L. Zhang, Y. Wang, Y. Ma, T. Guo and Y. Chen, Adv. Funct. Mater., 2009, 19, 2297-2302.

30 A. S. Asran, S. Henning and G. H. Michler, Polymer, 2010, 51, 868-876.

31 M. Koosha and H. Mirzadeh, J. Biomed. Mater. Res., Part A, 2015, 103, 3081-3093.

32 Q. Wang, J. L. Mynar, M. Yoshida, E. Lee, M. Lee, K. Okuro, K. Kinbara and T. Aida, Nature, 2010, 463, 339.

33 E. A. Appel, X. J. Loh, S. T. Jones, F. Biedermann, C. A. Dreiss and O. A. Scherman, J. Am. Chem. Soc., 2012, 134, 11767-11773.

34 A. K. Gaharwar, A. Arpanaei, T. L. Andresen and A. DolatshahiPirouz, Adv. Mater., 2016, 28, 771-781.
35 Y. Si, L. Wang, X. Wang, N. Tang, J. Yu and B. Ding, Adv. Mater., 2017, 29, 1700339.

36 D. Caccavo, S. Cascone, G. Lamberti and A. A. Barba, Mol. Pharmaceutics, 2014, 12, 474-483.

37 P. I. Lee, J. Controlled Release, 1985, 2, 277-288.

38 D. L. Taylor and M. in het Panhuis, Adv. Mater., 2016, 28, 9060-9093.

39 J. Ma, J. Lee, S. S. Han, K. H. Oh, K. T. Nam and J.-Y. Sun, ACS Appl. Mater. Interfaces, 2016, 8, 29220-29226.

40 J. Gibson, D. Wray and J. Bagg, Oral Surg., Oral Med., Oral Pathol., Oral Radiol. Endodontol., 2000, 89, 171-176.

41 J. Lugrin, N. Rosenblatt-Velin, R. Parapanov and L. Liaudet, Biol. Chem., 2014, 395, 203-230.

42 D. Aframian, T. Davidowitz and R. Benoliel, Oral Dis., 2006, 12, 420-423.

43 C. Duval and M. Poelman, J. Pharm. Sci., 1995, 84, 107-110. 44 R. Jayakrishnan, K. Chang, G. Ugurluer, R. C. Miller and T. T. Sio, Oncol. Rev., 2015, 9, 290.

45 I. De Angelis and L. Turco, Curr. Protoc. Toxicol., 2011, 47, 20.26.21-20.26.15.

46 X. Lin, X. Huang, C. Zeng, W. Wang, C. Ding, J. Xu, Q. He and B. Guo, J. Colloid Interface Sci., 2019, 535, 491-498.

47 Y. Guan, L. Shao, D. Dong, F. Wang, Y. Zhang and Y. Wang, RSC Adv., 2016, 6, 69966-69972.

48 Y.-N. Chen, L. Peng, T. Liu, Y. Wang, S. Shi and H. Wang, ACS Appl. Mater. Interfaces, 2016, 8, 27199-27206.

49 K. H. Hong, Fibers Polym., 2016, 17, 1963-1968.

50 L.-D. Koh, Y. Cheng, C.-P. Teng, Y.-W. Khin, X.-J. Loh, S.-Y. Tee, M. Low, E. Ye, H.-D. Yu and Y.-W. Zhang, Prog. Polym. Sci., 2015, 46, 86-110.

51 S. Keten, Z. Xu, B. Ihle and M. J. Buehler, Nat. Mater., 2010, 9, 359.

52 J. Su, Q. Wang, R. Su, K. Wang, Q. Zhang and Q. Fu, J. Appl. Polym. Sci., 2008, 107, 4070-4075.

53 T. Steiner, Angew. Chem., Int. Ed., 2002, 41, 48-76.

54 M. Hasany, A. Thakur, N. Taebnia, F. B. Kadumudi, M.-A. Shahbazi, M. K. Pierchala, S. Mohanty, G. Orive, T. L. Andresen and C. B. Foldager, ACS Appl. Mater. Interfaces, 2018, 10, 34924-34941.

55 T. L. Sun, T. Kurokawa, S. Kuroda, A. B. Ihsan, T. Akasaki, K. Sato, M. A. Haque, T. Nakajima and J. P. Gong, Nat. Mater., 2013, 12, 932.

56 G. Li, H. Zhang, D. Fortin, H. Xia and Y. Zhao, Langmuir, 2015, 31, 11709-11716.

57 J.-Y. Sun, X. Zhao, W. R. K. Illeperuma, O. Chaudhuri, K. H. Oh, D. J. Mooney, J. J. Vlassak and Z. Suo, Nature, 2012, 489, 133.

58 G. Dong, H. Liu, X. Yu, X. Zhang, H. Lu, T. Zhou and J. Cao, Nat. Prod. Res., 2018, 32, 2225-2228.

59 H. Akiyama, K. Fujii, O. Yamasaki, T. Oono and K. Iwatsuki, J. Antimicrob. Chemother., 2001, 48, 487-491.

60 A. Scalbert, Phytochemistry, 1991, 30, 3875-3883.

61 N. Sahiner, S. Sagbas, M. Sahiner, C. Silan, N. Aktas and M. Turk, Int. J. Biol. Macromol., 2016, 82, 150-159.

62 R. Coates, J. Moran and M. J. Horsburgh, Future Microbiol., 2014, 9, 75-91. 
63 J. P. O'gara, Environ. Microbiol., 2017, 19, 3823-3833.

64 Y. N. Slavin, J. Asnis, U. O. Häfeli and H. Bach, J. Nanobiotechnol., 2017, 15, 65.

65 B. Boonkaew, M. Kempf, R. Kimble, P. Supaphol and L. Cuttle, Burns, 2014, 40, 89-96.

66 P. V. AshaRani, G. Low Kah Mun, M. P. Hande and S. Valiyaveettil, ACS Nano, 2008, 3, 279-290.

67 P. Hupkens, H. Boxma and J. Dokter, Burns, 1995, 21, 57-61.

68 M. L. Mota, G. Thomas and J. M. F. Barbosa, J. Ethnopharmacol., 1985, 13, 289-300.

69 M. M.-Y. Chan, D. Fong, C.-T. Ho and H.-I. Huang, Biochem. Pharmacol., 1997, 54, 1281-1286.
70 M. Sobeh, M. F. Mahmoud, R. A. Hasan, M. A. Abdelfattah, O. M. Sabry, M. A. Ghareeb, A. M. El-Shazly and M. Wink, Sci. Rep., 2018, 8, 9343.

71 G. Frasca, V. Cardile, C. Puglia, C. Bonina and F. Bonina, Clin. Exp. Gastroenterol., 2012, 5, 61.

72 D. Pattarayan, A. Sivanantham, V. Krishnaswami, L. Loganathan, R. Palanichamy, S. Natesan, K. Muthusamy and S. Rajasekaran, J. Cell. Physiol., 2018, 233, 2513-2525.

73 M. Koland, R. N. Charyulu, K. Vijayanarayana and P. Prabhu, Int. J. Pharm. Invest., 2011, 1, 164.

74 J. Rajeev, S. Mukundan, B. K. Raj, V. Dhanaja, T. Subburaj and K. Kamalasanan, J. Pharm. Sci. Res., 2018, 10, 2079-2083. 